\section{Tipologías domésticas y técnicas constructivas en la primitiva Gasteiz (País Vasco) durante los siglos vilI al XII d.C.}

\section{Domestic and technical building types in the early Gasteiz (Basque Country) in the $8^{\text {th }}-12^{\text {th }}$ centuries}

\author{
Agustín Azkarate Garai-Olaun*
}

José Luis Solaun Bustinza

Universidad del PaísVasco/Euskal Herriko Unibersitatea

\begin{abstract}
Resumen
En este trabajo se expone, de manera sintética, la evolución de la arquitectura y de los espacios construidos en el principal centro urbano del País Vasco durante el Medievo más temprano. El contenido del artículo atiende únicamente a la dimensión física de cuantas conforman los significantes y significados del universo doméstico (su configuración espacial y sus técnicas constructivas), documentando hasta cuatro modelos que se suceden en el tiempo (los espacios domésticos desagregados, los espacios domésticos más compactos, la casa unitaria y la casa en altura) y advirtiendo, en consecuencia, sobre los riesgos derivados de las generalizaciones abusivas que generan imágenes planas y estáticas del universo doméstico de época medieval.
\end{abstract}

Palabras clave: Edad Media, Vitoria-Gasteiz, unidad doméstica, arquitectura, sistemas constructivos, urbanismo.

\begin{abstract}
This paper provides a summary of the development of architecture and built spaces in the largest urban centre in the Basque Country in the early middle ages. Of the many aspects that make up the signifiers and significances of the domestic universe, this paper only approaches the material aspect; that is, its spatial layout and building techniques. Four models that succeed each other are documented: separate domestic spaces, more compact domestic spaces, the unitary house and storeyed house. It also warns against the danger of abusive generalizations caused by flat, static images of the medieval domestic universe.
\end{abstract}

Keywords: middle ages, Vitoria-Gasteiz, domestic unit, architecture, constructive systems, urbanism.

\footnotetext{
*agustin.azcarate@ehu.es / joseluis.solaun@ehu.es.

Grupo de Investigación en Patrimonio Construido (GPAC). Universidad del País Vasco/Euskal Herriko Unibertsitatea. Centro de Investigación y Estudios Avanzados «Lucio Lascaray». Av. Miguel de Unamuno, 3. 01006, VitoriaGasteiz. (http://www.arqueologiadelaarquitectura.com). Este trabajo ha sido realizado con fondos procedentes del Programa TCP (CSD2007-00058) Consolider Ingenio 2010, financiado por el Ministerio de Ciencia e Innovación y titulado Programa de investigación en tecnologías para la valoración y conservación del Patrimonio Cultural CSD-TCP.
}

\section{INTRODUCCIÓN}

Como hemos apuntado en alguna otra ocasión (Azkarate 2008, 2011, e.p.), los estudios sobre arquitectura llevados a cabo desde la arqueología («arqueología de la arquitectura») tienen un larga trayectoria historiográfica, con tradiciones académicas diversas y enfoques conceptuales múltiples, en una suerte de proceso cognitivo colectivo que presintió y anticipó desde siempre (ya desde la conocida trilogía vitrubiana), la pluralidad de dimensiones que laten en el corazón de cualquier espacio construido. Nada hay nuevo por lo tanto bajo el sol, por mucho que la irrefrenable pasión por los nominalismos y «la neblina característica de una amnesia moderna que conduce a gestos intelectuales repetitivos» (Witmore, 2007) genere, de manera pertinaz, pretendidas reformulaciones en la bibliografía más reciente.

En ese universo de temáticas y enfoques diversos, la arquitectura doméstica es probablemente una de las parcelas que menos atención ha recibido en la Europa meridional, a pesar de contar con una sólida tradición historiográfica anglosajona y latinoamericana (Steadman, 1996; Zarankin, 2005; Azkarate, e.p.).

Desde que, en las décadas de los 60 a los 80 , la «arqueología de los asentamientos» orientara sus estudios hacia los análisis tanto macroespaciales de los patrones de asentamiento como por los estudios microespaciales más específicos, las unidades domésticas se concibieron como escenarios de actividades que, en su diversidad, reflejaban los comportamientos sociales de quienes las habitaron. Fue precisamente en el ámbito micro y semimicro donde la «arqueología de los espacios domésticos» (Wilk, Rathje, 1982) alcanzaría un desarrollo notable, marcando las pautas de renovación de las tradicionales aproximaciones a la arquitectura y acabar prestando más atención al escenario mismo como espacio construido. El excesivo peso de los intereses positivistas, sin embargo, hizo que se priorizaran las estrategias funcionalistas orientadas al estudio de las dimensiones físicas y visibles del espacio construido en detrimento de la dimensión no visible y de sus significados simbólicos.

Habría que esperar a los 90 para que se formulasen nuevas propuestas más orientadas hacia el conocimiento de los significados de la arquitectura y de los espacios construidos. Todas ellas beberán de precedentes que, desde la antropología y la arquitectura (Rapoport, 1976), la geografía y el urbanismo (Hillier, Hanson, 1984), la sociología (Bourdieu, 1972), la filosofía (Heidegger, 1994, 1951; Foucault, 1984) o la semiótica (Eco, 1968) venían insistiendo en la necesidad de contemplar los espacios construi- 

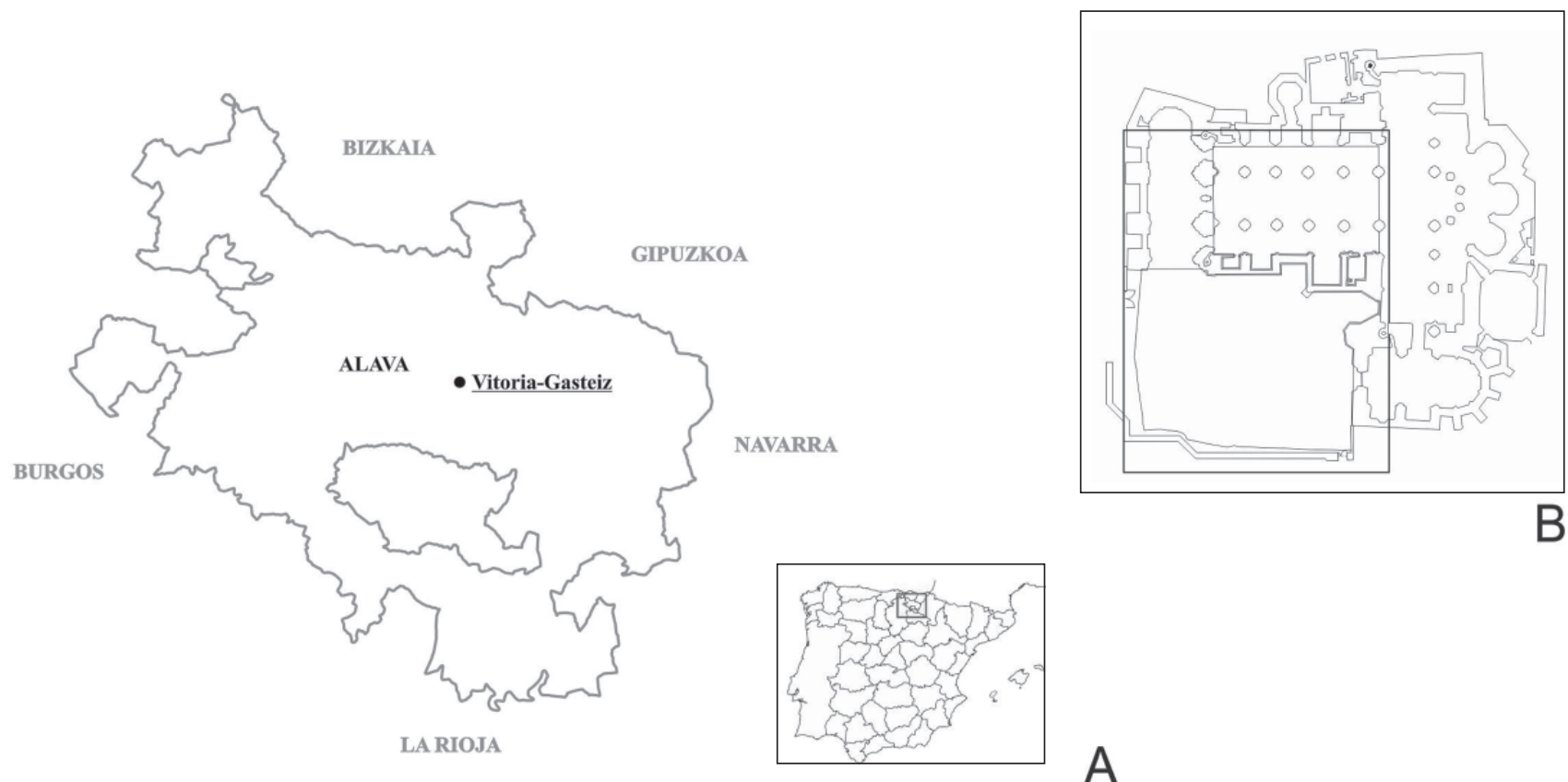

Fig. 1. A. Mapa de situación de Vitoria-Gasteiz; B. Área excavada con metodología arqueológica en la Catedral de Santa María

dos no sólo como portadores sino como generadores también de significados. En este nuevo contexto, los espacios habitados, y la casa ante todo, acabarán viéndose como un "cosmograma» (Nielsen, 2001) en el que todas las cosas hablan metafóricamente y en el que los humanos aprenden a leer el mundo.

La historia de los espacios construidos devendrá, consecuentemente, en una topografía de las complejas constelaciones cotidianas, susceptibles de ser estudiadas desde nuevas propuestas metodológicas procedentes de la etnoarqueología (González Ruibal, 2001), de los campos de la semiótica, del spatial syntax o de los estudios proxémicos sobre la territorialidad (Bermejo, 2009), por citar solamente algunas de las más relevantes.

En esta ocasión, nuestros objetivos van a ser mucho más humildes y específicos y atenderemos sólo a la dimensión más física de cuantas conforman los significantes y significativos del universo doméstico: su configuración espacial y sus técnicas constructivas. Todo ello referido a una horquilla cronológica que transcurre entre los siglos VIII y XII d.C. y a un ámbito geográfico circunscrito a la ciudad de Vitoria-Gasteiz.

\section{TIPOLOGÍAS DOMÉSTICAS}

En las sucesivas campañas de excavación arqueológica llevadas a cabo durante los años 2000 al 2009, tanto en el interior de la Catedral de Santa María de Vitoria como en sus inmediaciones, al exterior de la misma, se fueron registrando testimonios materiales de diversas estructuras distribuidas en el espacio, organizadas aparentemente en áreas distintas, con funcionalidades específicas. De tales testimonios pronto pudo inferirse la presencia de ámbitos domésticos que, con distintas configuraciones, se sucedían a lo largo de los siglos (Azkarate 2007, Azkarate, Solaun, 2009). El objetivo principal de nuestra investigación ha sido el de decodificar la evolución de dichas unidades domésticas definiendo, primero, sus rasgos morfológicos y constructivos; tratando luego de determinar la funcionalidad de los mismos; y registrando, finalmente, la variabilidad de los distintos patrones que las unidades domésticas iban adquiriendo con el tiempo. Este último punto resulta particularmente interesante en la medida que coadyuva a la superación de inferencias de tipo anacrónico (Bermejo, $2009,58)$ nacidas de la aplicación de modelos interpretativos estáticos y que saltan por los aires en cuanto se someten al análisis exhaustivo en un asentamiento que evolucionó ininterrumpidamente durante siglos (Gutiérrez Lloret, Cañavete, 2010). Fijémonos, brevemente, en las variantes más significativas.

\subsection{Espacios domésticos desagregados (700-950 d.C.)}

El sector más septentrional del cerro donde nació la primitiva aldea de Gasteiz (origen de la actual ciudad de Vitoria-Gasteiz) estuvo ocupado desde sus orígenes por una unidad doméstica que, en conjunto, alcanzó una 


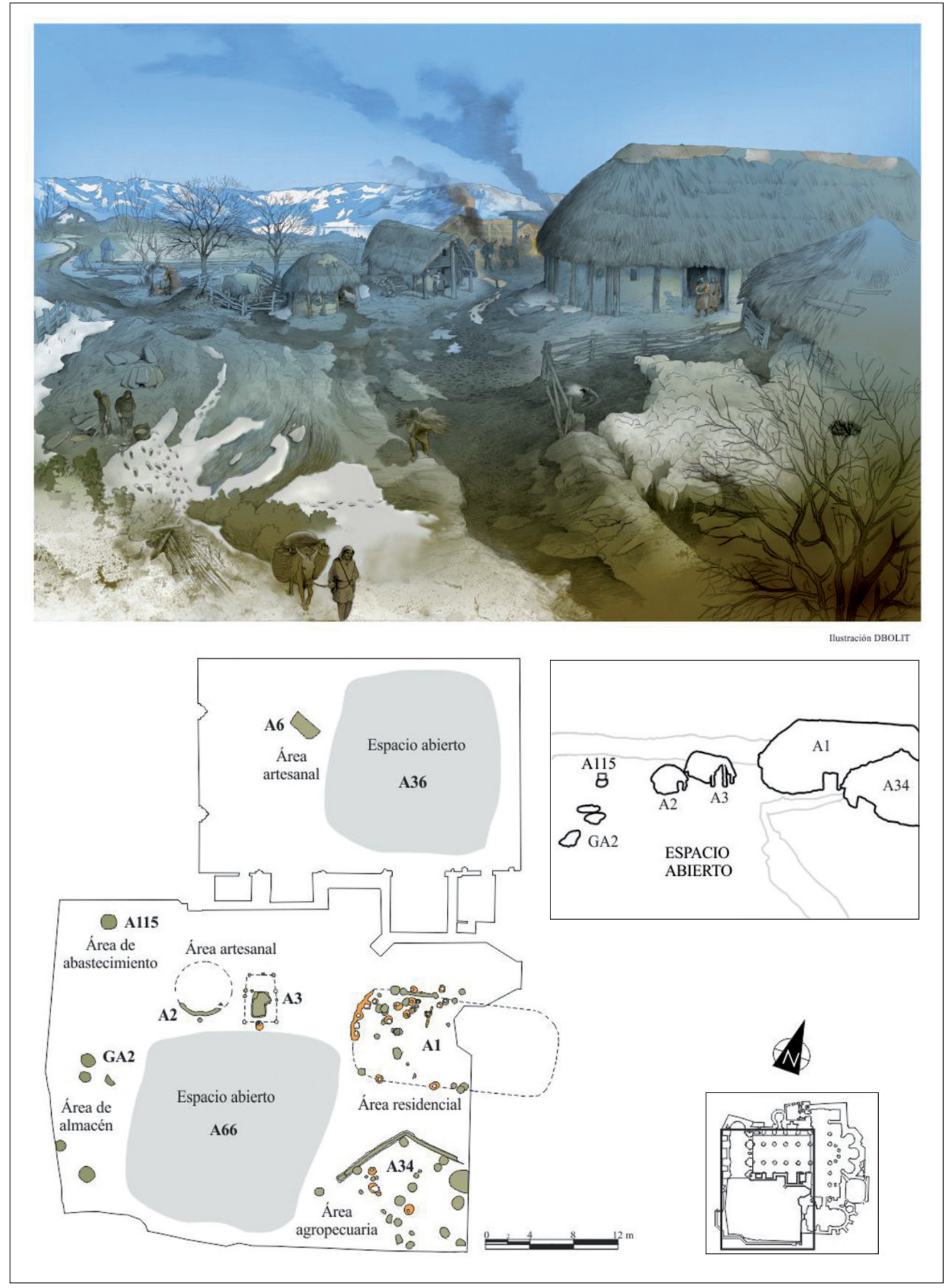

Fig. 2. Recreación -con base en el registro arqueológico- de la unidad doméstica documentada entre los años 850-950 d.C. Espacios domésticos desagregados 
extensión superior a los 2.000 metros cuadrados. En su larga historia pasó por distintas fases, bien detectadas arqueológicamente (Azkarate, Solaun, 2009), pero mantuvo siempre una disposición configuracional básica en torno a dos espacios abiertos que articulaban y organizaban el resto de las estructuras que componen el complejo habitacional. El esquema, como se ve, parte de la concepción de la casa como agregación de estructuras que, dispuestas en torno a espacios abiertos (a modo de cortiles o corrales), se distribuyen en un primer momento de manera dispersa y desagregada, poco cohesionada formalmente, para ir compactándose progresivamente en el tiempo. Desde fechas tempranas, por lo tanto, el rasgo más característico de esta forma de ocupación altomedieval es el de la segmentación espacial de su arquitectura y la presencia de ambientes bien delimitados unos respecto de otros, independientemente de que estén o no construidos y configuren espacios formalmente abiertos o cerrados.

Esta separación de espacios, perfectamente detectable en el registro arqueológico, tiene sin duda una honda significación en la medida en que responde a la voluntaria creación de escenarios orientados a actividades específicas. Todos ellos, espacios y actividades, modelaron el built environment que configuró el universo cotidiano de sus habitantes y en el que se desarrollaron los sucesivos patrones de su actividad doméstica.

Nos fijaremos en esta ocasión en la configuración (Figura 2) que dicha unidad doméstica alcanzó entre mediados del siglo IX y mediados de la centuria siguiente (ca. $850-950$ d.C. $)^{1}$ y que estuvo constituida, como se ha señalado ya, por dos ámbitos bien diferenciados.

El primero de ellos se articulaba en torno al espacio abierto A66 y comprendía las siguientes áreas de actividad: a) Una primera de carácter residencial (A1), representada por un gran edificio (longhouse) de aproximadamente $18 \mathrm{~m}$ de longitud y $8,5 \mathrm{~m}$ de anchura; b) Una segunda de naturaleza artesanal, con dos pequeñas cabañas (A2 y A3) destinadas muy probablemente a actividades textiles, a juzgar por las semillas de lino y las fusayolas recogidas en sus contextos estratigráficos; c) Una tercera destinada a almacenamiento de excedentes agrícolas (GA2), con un mínimo de cinco silos excavados en el subsuelo; d) Una cuarta (A34), de uso agropecuario, con un recinto destinado posiblemente a la estabulación de la cabaña ganadera a juzgar por los estudios palinológicos y de fauna detectados (Ibidem: 413); d) Una quinta, interpretable como área de

\footnotetext{
${ }^{1}$ Hubo una configuración anterior (entre 700 y 850 d.C.) que no abordaremos
} en esta ocasión, pero que puede consultarse en Azkarate, Solaun, 2009. evacuación de los residuos domésticos generados por la unidad, que se sirvió de los silos que quedaban en desuso para su reutilización como basureros; e) Una sexta de abastecimiento que, en forma de pozo (A115), surtía de agua a este espacio doméstico y probablemente también a algún otro de su entorno; f) Y una última, probablemente la más significativa de todas, representada por el espacio abierto A66, escenario de actividades diversas y relaciones sociales múltiples.

Inmediatamente al norte, en las traseras de $\mathrm{A} 1, \mathrm{~A} 2 \mathrm{y}$ A3, se configuró un segundo ámbito caracterizado por un fondo de cabaña (A6), que sustituye a otro anterior en cuyo suelo y niveles de amortización aparecieron numerosos carbones y escorias, y un gran espacio abierto (A36). Estamos ante un área de actividad específica y segregada de la unidad doméstica principal que ha podido ser identificado con un espacio de trabajo siderometalúrgico (Azkarate, Solaun, 2009).

Resulta casi imposible, a la vista del registro arqueológico, no recordar el socorrido testimonio de Valpuesta del año 975 en el que se mencionan kasas cum suos solares et suas divisas, et exitos et introitos, et sua hera qui est ad illa porta, cum suo orto et suo korro et suas adiacentias ad toto giro qui ad ipsas casas pertinent; et sunt ipsas casas in villa que uocitant Elezeto, latus kasa de Didaco; et de ilia partelatus casa de Munnio Amuscoz, et tertia et quarta latus campo qui est exito de villa (Pérez Soler, 1970: 66), reflejando de manera descriptiva la forma en que estas casas se distribuían sobre el terreno, unas junto a otras, adoptando un patrón de naturaleza alveolar nacido de la yuxtaposición de las diferentes unidades domésticas.

\subsection{Espacios domésticos más compactos: viviendo en torno a un patio ( $2^{\mathrm{a}}$ mitad siglo $\mathrm{x}$ )}

Algunas de las estructuras descritas en el punto anterior fueron amortizadas tras un importante incendio que explica, muy probablemente, las transformaciones que conoció el lugar a mediados del siglo X. La profundidad y alcance de dichas transformaciones fue tal que una parte de las estructuras descritas quedó sepultada bajo potentes nivelaciones y aterrazamientos que modificaron sustancialmente la orografía del lugar.

Lo cierto es que la nueva nivelación favoreció una urbanización más racional de los espacios y la creación de un nuevo modelo de casa, más compacto que el anterior y estructurado inequívocamente en torno a un patio de límites mucho más precisos. Pese a su mayor racionalidad, esta tipología apenas se dilató media centuria en el tiempo. El cruce de resultados entre la secuencia estratigráfica, los 


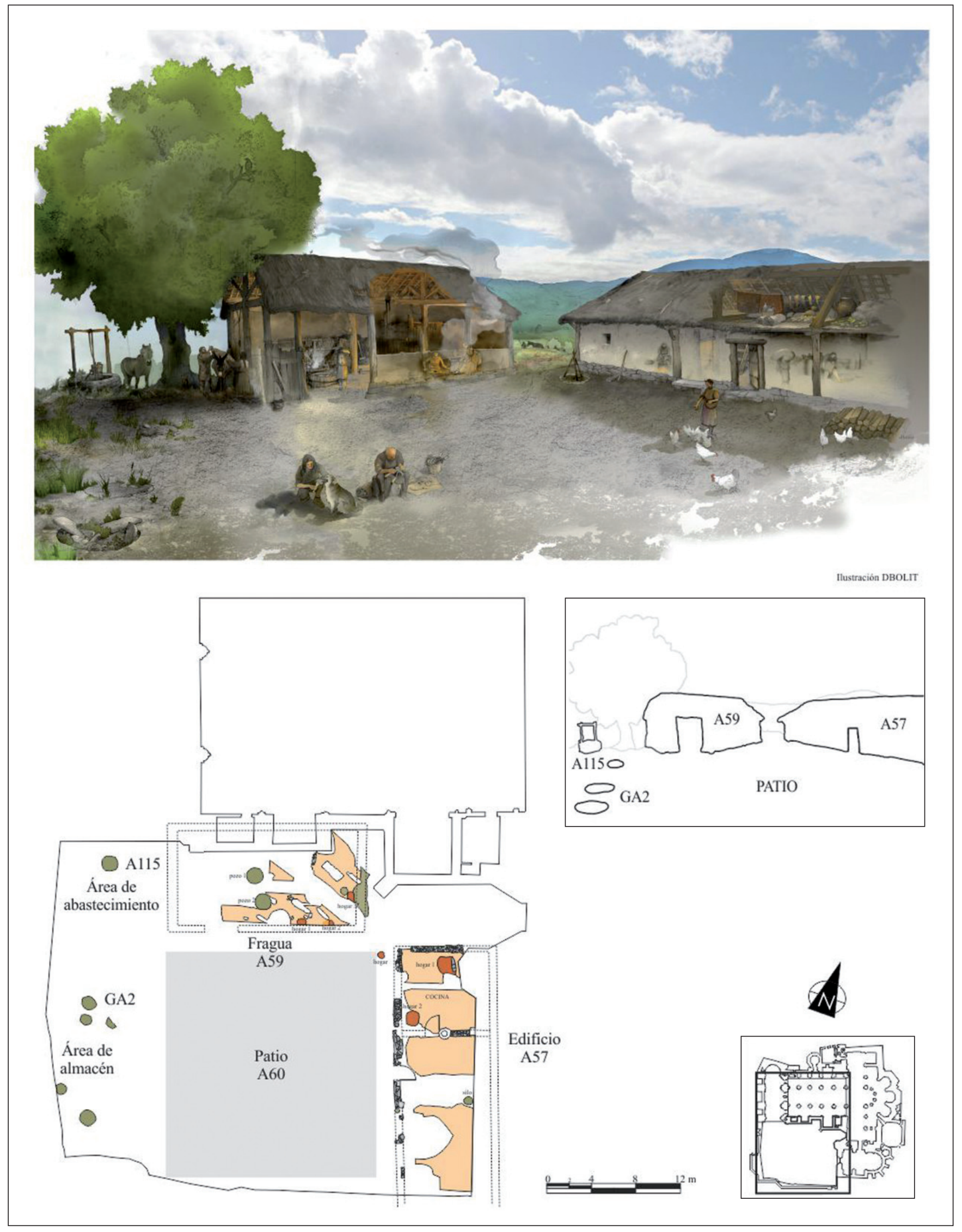

Fig. 3. Recreación -con base en el registro arqueológico- de la «casa con patio» en la segunda mitad del siglo x d.C. 
análisis radiocarbónicos y los materiales cerámicos recuperados en los rellenos constructivos que nivelan los edificios que integran esta casa permiten fijar su cronología en la segunda mitad del siglo X, coincidiendo (y ello no deja de tener su significación, como luego veremos) con la aparición de la piedra como material constructivo en la arquitectura doméstica altomedieval de nuestro ámbito geográfico. Son varios los puntos que llaman la atención de esta variante del modelo primitivo:

a) La regularidad de su trazado (Figura 3), resultado, como sabemos, de un plan previamente diseñado.

b) Su gran patio A60, situado de manera más ordenada sobre el viejo espacio A66 y convertido ahora en escenario de una parte importante tanto de las ocupaciones sociales y familiares (fuegos bajos que evidencian puntos de reunión social, preparación y consumo de alimento) como de las actividades económicas (hallazgo de yunques de hueso utilizados por los herreros para afilar hoces que denotan su uso como espacio de trabajo ferrón ${ }^{2}$ ).

c) El gran edificio (A57) que se construyó en el lado oriental de dicho patio sobre el mismo emplazamiento que ocuparan la longhouse (A1) y el recinto ganadero (A34), conformado como una gran estructura rectangular de más de 30 metros de longitud, 7,80 metros de anchura y una superficie conservada de $230 \mathrm{~m}^{2}$. Esta notable construcción comunicaba directamente con el patio a través de un acceso emplazado en su fachada occidental. Tras el umbral, ya en su interior, se situaba un espacio diáfano y multifuncional que ocupaba más de dos tercios de la superficie total y contenía un silo de almacenamiento. Por su lado septentrional se accedía a otra estancia de dimensiones menores en cuyo interior pudieron registrarse hasta dos suelos superpuestos sobre los que dispusieron tres hogares, dos de los cuales funcionaron simultáneamente.

d) Uno de los aspectos más reseñables será, finalmente, la incorporación al espacio doméstico de una actividad que, hasta entonces, había permanecido segregada de este ámbito. Como puede verse en la planimetría que se adjunta, en el lado septentrional del patio y sobre el lugar que en la fase anterior ocupaban dos edificaciones auxiliares (A2 y A3), se construyó una fragua (A59), trasladando la antigua instalación ferrona al corazón mismo de la nueva unidad doméstica. Lo más destacable, arqueológicamente,

\footnotetext{
${ }^{2}$ Como señalábamos en un trabajo anterior (Azkarate, Solaun, 2009: 420), los yunques de hueso destinados al dentado de hoces, a su afilado o a reavivar los dientes desgastados por el uso, han sido utilizados por los herreros hasta bien entrado el siglo Xx. Se trata siempre de huesos de bóvido o caballo con sus diáfisis facetadas y alisadas, con series de incisiones dispuestas en bandas paralelas como consecuencia del cincelado perpendicular sobre el borde cortante de la hoz y la superficie ósea.
}

de este nuevo establecimiento es sin duda la conservación de un suelo sobre el que se situaron tres hogares bajos y dos depósitos de agua destinados sumergir y templar el hierro candente. Estas estructuras de combustión y la conservación del propio suelo son precisamente los elementos que permiten definir la forma y dimensiones del taller, de planta rectangular y $130 \mathrm{~m} 2$ de superficie, con algunos alzados semiabiertos para la libre salida de humos y gases.

\subsection{La calle como nuevo espacio estructurador: la casa unitaria multifuncional (siglo XI d. C.)}

Con el cambio de milenio, Gasteiz incorpora a su trazado una trama urbana organizada en tres calles paralelas que transformará radicalmente el antiguo paisaje construido. El viejo esquema alveolar (ya debilitado con la regularización descrita para el periodo anterior) desaparece definitivamente y se adopta un nuevo sistema de edificios residenciales alineados a ambos lados de las nuevas calles. Se abandona así el modelo de casa con patio (que seguirá perdurando todavía durante siglos en ambientes más específicamente campesinos) para ser substituido por un nuevo tipo de casa conformada por un único edificio multifuncional que reúne bajo el mismo techo los espacios de uso residencial, artesanal o de almacén que anteriormente se ubicaban en estructuras desagregadas.

La nueva casa mantiene la traza y estructura del primitivo edificio A57 aunque, en su interior, se levantan tres medianiles que dividirán el conjunto en al menos tres estancias uniformes e independientes entre sí, cada una de ellas con su propio acceso individual desde la calle pavimentada del exterior. Estamos ante una tipología, bien conocida en otros ámbitos europeo, que yuxtapone bajo el mismo techo diversos espacios con funciones específicas.

Dentro del primer ambiente (A71), de amplia planta cuadrangular $\left(50 \mathrm{~m}^{2}\right)$, se registraron hasta cuatro estructuras de combustión diferentes, dato éste que, junto a la abundancia de escorias, lleva a pensar en su función como taller metalúrgico, heredero de la antigua fragua A59. La aparición de un buen número de yunques de hueso sobre el empedrado exterior, a la altura del umbral, confirma esta $\operatorname{actividad}^{3}$ y denuncia además el uso de la calle como área de actividad multifuncional.

En el interior del segundo ambiente (A72), similar en dimensiones al descrito, se documentó un hogar de cuidada factura, protegido por un murete de adobe, que debió de cumplir funciones culinarias y de calefacción. El am-

\footnotetext{
${ }^{3}$ Cfr. nota anterior.
} 


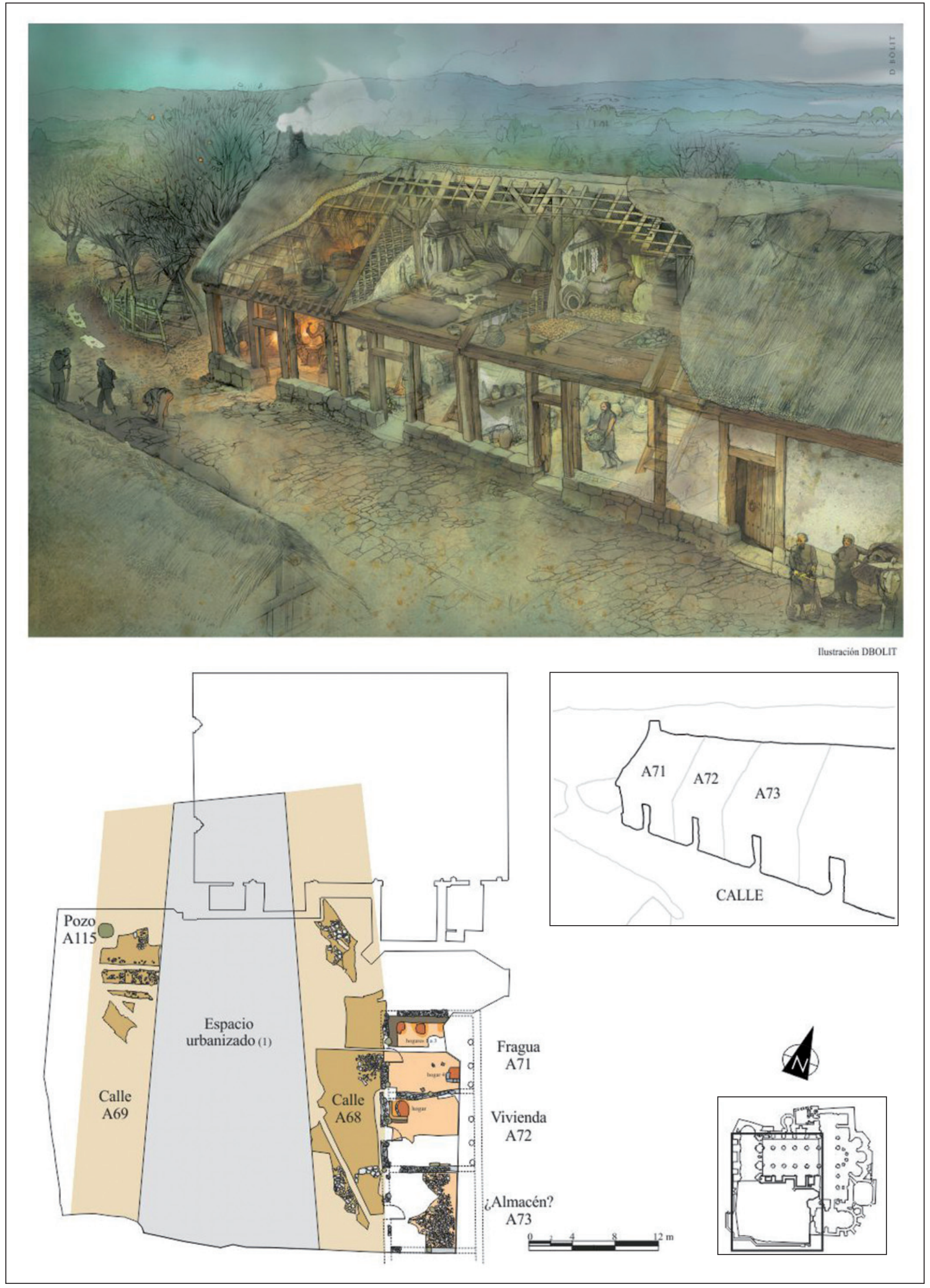

Fig. 4. Recreación -con base en el registro arqueológico- de la «casa unitaria» y de la nueva trama urbana de Gasteiz (siglo XI d.C.). (1) Los restos de época altomedieval registrados en el espacio entre las dos calles, estaban profundamente alterados por la urbanización de los siglos XIV y XV, lo que desaconseja efectuar proyecciones sobre el mismo 


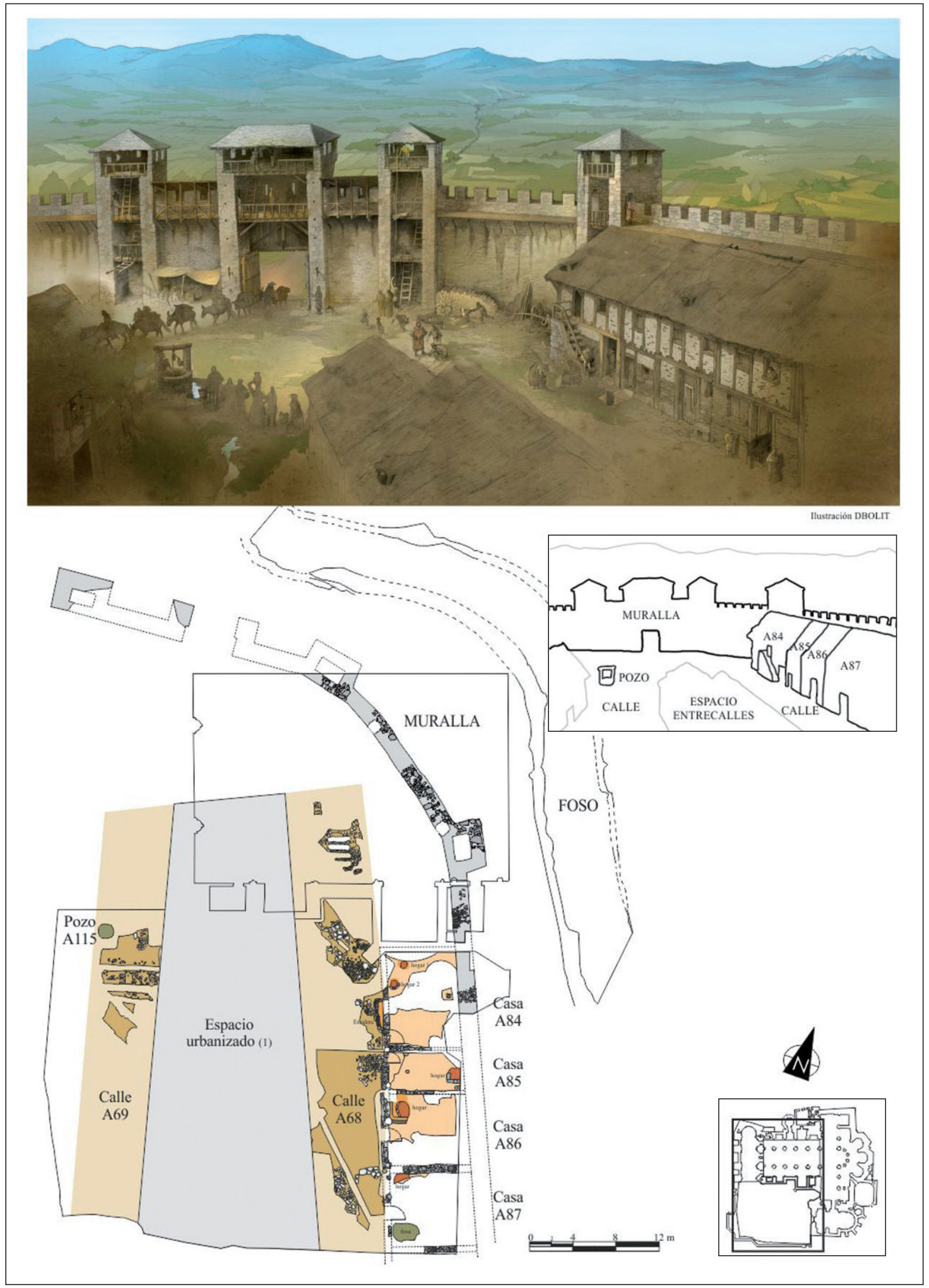

Fig. 5. Recreación — con base en el registro arqueológico— de la profunda modificación urbana acontecida en los primeros decenios del siglo XII d.C., con la «casa en altura» a la derecha. (1) (1) Los restos de época altomedieval registrados en el espacio entre las dos calles, estaban profundamente alterados por la urbanización de los siglos XIV y xv, lo que desaconseja efectuar proyecciones sobre el mismo 
biente restante (A73), similar a los descritos en dimensiones, debió ser utilizado como dormitorio y/o eventual espacio de almacenaje.

\subsection{La densificación de la trama urbana y la aparición de la casa en altura (siglo XII d.C.)}

El último episodio en la evolución de los espacios domésticos que estamos describiendo concluye con la casa en altura, surgida durante el siglo XII en el proceso de densificación de la trama urbana que debió de suceder al amurallamiento de Gasteiz (Azkarate, Solaun, 2009).

Será en este contexto cuando el primitivo edificio se reconstruye ganando altura y generando un nuevo inmueble que superpone las diversas áreas de actividad en lugar de yuxtaponerlas como en el caso anterior. Se rompe así la estructura horizontal de la casa unitaria y se crea un nuevo modelo arquitectónico que desarrolla su programa en vertical mediante la superposición de uno o varios pisos superiores, resultando cuatro casas contiguas donde antes sólo había una.

Un ejemplo representativo es el edificio situado en el extremo norte (A84). Su planta baja, de aproximadamente $50 \mathrm{~m}^{2}$, mantendrá su actividad artesanal heredera de la que tuvo A71, con dos estructuras de combustión bien documentadas en su ángulo noroccidental. En el piso superior se situaba el área de habitación y en el desván o bajocubierta la zona de almacenamiento. Esta nueva articulación espacial generará accesos independientes para la fragua y la vivienda. A la primera se entraba directamente desde la cota de la calle, mientras que el acceso a la segunda se efectuaba por un patín o escalera exterior que, además de dar acceso directo a la vivienda, permitía ganar espacio útil a costa de ocupar parte de la vía pública (Figura 5).

La segunda casa (A85) ocupaba un estrecho solar de apenas $20 \mathrm{~m}^{2} \mathrm{y}$, a juzgar por la ausencia de indicadores materiales que inviten a pensar en prácticas artesanales, debió de cumplir una función básicamente residencial. En su planta baja se situó la cocina, con un suelo de arcilla y un hogar en torno al cual se documentó un importante ajuar cerámico compuesto principalmente por ollas y orzas, además de una gran concentración de leguminosas almacenadas en sacos de tela. Una escalera situada frente a la puerta daba acceso al primer piso, de uso habitacional, $\mathrm{y}$ a un desván que sirviera de almacenamiento.

El tercero de los inmuebles (A86) configuró también una vivienda de aproximadamente $45 \mathrm{~m}^{2}$ por planta, que reproducía la organización espacial ya descrita en el caso anterior.
Más dudas existen respecto a la funcionalidad de A87. Los escasos restos conservados en su planta baja (un pequeño suelo de tierra con su hogar en esquina, una fosa de considerables dimensiones y varios apoyos pertenecientes al armazón lígneo de un forjado superior) sólo permiten certificar la existencia de un nuevo edificio con varias plantas, siendo difícil aportar algún dato sobre la funcionalidad de ninguna de ellas.

\section{MATERIALES CONSTRUCTIVOS}

\subsection{La madera}

La madera y el barro fueron los materiales utilizados, casi de manera exclusiva, en la arquitectura doméstica levantada entre los siglos VIII y X en Gasteiz. Es lo que cabe deducir del material recuperado en los niveles de amortización de los edificios (revestimientos de arcilla y madera carbonizada) y de las trazas arqueológicas de su arquitectura, reconocibles en forma de improntas negativas (rozas, agujeros y fosas). Algunos de estos agujeros aún conservaban la huella de los pies derechos de madera, de sección mayoritariamente cuadrangular (entre 20 y $40 \mathrm{~cm}$. de lado), conservando algunos de sus rellenos los restos del propio poste carbonizado.

Los análisis antracológicos efectuados a estas maderas han confirmado la utilización preferente del roble como material de construcción para las estructuras portantes, algo lógico si tenemos en cuenta sus excelentes propiedades mecánicas y el predominio de esta especie en la masa forestal del entorno geográfico más inmediato. Menos frecuente fue el haya, principalmente por la mayor dificultad que conllevaba su acopio, al emplazarse sus zonas de captación en áreas de montaña más alejadas. Probablemente fue usada también en la construcción, aunque no tanto para las estructuras portantes como para los suelos y tablazones interiores.

Los avellanos y fresnos son otras de las especies documentadas en el registro arqueobotánico que también debieron destinarse para la construcción, al ser especialmente apropiadas para elaborar el trenzado de los zarzos que componían gran parte de las paredes. Aún hoy en día, de hecho, numerosas casas rurales del norte peninsular muestran todavía la pervivencia de esta vieja técnica, restringida, eso sí, a las compartimentaciones internas de los edificios.

Las techumbres debieron construirse con ramajes vegetales, tablillas de roble o haya, e incluso céspedes o tapines. No hay, desde luego, evidencias de paja de centeno en los análisis carpológicos, como cabría esperar por los ejemplos conocidos en otras latitudes. 


\subsection{El barro}

Si la madera fue el material más utilizado en los suelos y estructuras portantes de los edificios, el barro lo será en los alzados. Su empleo se realiza mayoritariamente en forma de pellas de barro crudo colocadas sobre zócalos de piedra (façonnage direct) y de manteados de arcilla aplicada sobre los zarzos (clayonnage), de los que la intervención arqueológica ha recuperado varios fragmentos, fundamentalmente revestimientos marcados con las improntas vegetales de las varas de avellano o fresno (Figura 16). Asimismo es habitual su uso como revoque aplicado directamente sobre las paredes de los edificios. Menos frecuente es la aparición del barro secado al sol, como adobe, y prácticamente inexistente en su versión cocida, como ladrillo, para paredes de cierre o teja para las cubiertas.

La obtención de arcillas resultaba extremadamente fácil, al aflorar en buena parte de la colina de Gasteiz un estrato geológico aluvial de matriz arcillosa con algunas gravas de grano medio y fino. El acceso directo a este recurso por parte de los habitantes de la unidad doméstica exhumada en las excavaciones de la catedral de Santa María ha quedado documentado en el registro arqueológico con la presencia de un barrero de aproximadamente 80 $\mathrm{m}^{2}$ de superficie, cuya actividad se mantuvo constante entre los siglos VIII y IX. La extracción del material arcilloso se realizaba mediante la excavación de zanjas y hoyos de escasa profundidad (entre 20 y $40 \mathrm{~cm}$ ), al aprovechar únicamente los depósitos aluviales, respetando el substrato geológico de calizas margosas.

\subsection{La piedra}

Los años centrales del siglo $\mathrm{X}$ van a suponer un cambio substancial en lo que respecta a la arquitectura doméstica al incorporarse la piedra como material constructivo. El salto cualitativo era evidente, especialmente en lo concerniente a la durabilidad y consistencia de las estructuras. En este caso se trataba de caliza margosa extraída del propio substrato rocoso de la colina, un material que presentaba diversos hándicaps tanto desde el punto de vista de su resistencia mecánica (por ofrecer valores bajos de resistencia ante esfuerzos comprensivos no perpendiculares a la laminación) como desde su comportamiento ante las agresiones atmosféricas (principalmente por los cambios de humedad, ante los que se disgrega rápidamente; Martínez Torres, 1999: 11). A pesar de todo, y dadas las escasas cargas que transmitían los edificios construidos en aquellos momentos, está claro que, durante la décima y undécima centuria, pesaron más los criterios de accesibilidad a la piedra que los comportamientos mecánicos de la misma.
La mayor complejidad estructural de los edificios a partir del siglo XII, sin embargo, conllevará otras exigencias $\mathrm{y}$, en consecuencia, requerirá de los conocimientos de un ambiente técnico más elaborado. Es en este contexto en el que la débil caliza margosa local será sustituida por la calcarenita, un tipo de piedra que poseía también algún hándicap (su dificultad de labrar que la destinaba básicamente a mampuesto o sillarejo en el mejor de los casos) pero que ofrecía, en cambio, ventajas difíciles de rechazar como su gran dureza, su facilidad de extracción y la relativa cercanía de las canteras ${ }^{4}$.

La primera de las cualidades garantizaba unas propiedades geotécnicas suficientes para responder eficazmente a las tensiones de comprensión y flexión en los muros que derivaban del crecimiento en altura de las casas. La segunda no era menos desdeñable, puesto que los estratos afloraban horizontalmente en forma de diaclasas muy planas y no resultaba complicado extraer el material mediante cuñas. La presencia de amplias escombreras al pie de la contigua muralla refleja la labor de desbaste efectuada, posiblemente sobre andamio, lo que nos remite a ciclos constructivos más diversificados y a una mano de obra especializada.

Junto a la calcarenita se introdujo también la lumaquela, aunque para un uso restringido en partes muy precisas de las obras más importantes (esquinales, recerco de ventanas, detalles escultóricos, jambas y dinteles, etc). Su limitado empleo resulta lógico, en tanto que se trata de una piedra obtenida en canteras aún más distantes que la calcarenita, concretamente en las proximidades de la localidad treviñesa de Ajarte, situada a más de quince kilómetros de Gasteiz. Su alejada ubicación se ve compensada, no obstante, por su fácil y sencilla explotación, amén de ser una roca de baja dureza y gran maleabilidad (Ibidem: 10).

\subsection{Otros materiales}

La tardía aparición de muros de piedra en el primitivo asentamiento de Gasteiz, no fue óbice para que el empleo de la cal y el yeso esté presente ya en la estructuras altomedievales más madrugadoras. Los análisis microestratigráficos y petrográficos efectuados a algunos revestimientos recuperados en estos contextos determinaron, en efecto, la presencia de enlucidos compuestos por cal, yeso y

\footnotetext{
${ }^{4}$ Aunque la facies más representativa de esta roca se localiza en la parte alta del monte Olárizu, existen gran número de huecos de cantera en localidades como Lasarte, Arechavaleta, Gardelegui o Castillo, todas ellas próximas a Vitoria (Martinez Torres, 1999: 11).
} 
óxidos de hierro, que otorgaban a la superficie una tonalidad rosácea ${ }^{5}$.

Los materiales metálicos, en cambio, se reducen a unos pocos clavos de hierro que, atendiendo a sus pequeñas dimensiones (entre 27 y $37 \mathrm{~mm}$. de longitud), debieron emplearse para ebanistería o la tablazón de suelos y medianiles, nunca en las estructuras portantes de los edificios. Aunque sea lógico suponer la presencia de otros elementos de carpintería metálica tales como bisagras o tiradores, si bien el registro arqueológico no ha documentado ningún resto.

\section{TÉCNICAS CONSTRUCTIVAS}

\subsection{Estructuras portantes}

En este epígrafe se analizan los sistemas constructivos empleados en las estructuras portantes de los edificios, entre las que se han identificado cuatro tipos principales (de acuerdo con propuesta tipológica planteada por Fronza y Valenti, 1996):

4.1.1. Armadura de postes. Es, sin duda, el principal sistema portante utilizado en los edificios exhumados en Gasteiz para los siglos VIII y X d.C. Se caracteriza por la presencia de una armadura de postes embutidos directamente en el terreno, principalmente en el interior de agujeros y canaletas perimetrales, siguiendo diversas técnicas de disposición del suelo interno que han determinado tres variantes constructivas:

- Con pavimento sobreelevado. Se basa en la utilización de complejos armazones verticales de postes de roble, firmemente asentados en el terreno y destinados a soportar un pavimento sobreelevado de madera. El uso generalizado de este sistema no es casual: además de evitar la humedad en los suelos, permite asentar los diferentes edificios sobre la pendiente natural de la ladera (en ocasiones superior al 10\%) sin necesidad de modificar la geomorfología del terreno y, por tanto, sin una gran inversión de trabajo.

El caso más representativo lo constituye el edificio residencial A1, una longhouse de aproximadamente $18 \mathrm{~m}$ de longitud y $8,5 \mathrm{~m}$ de anchura donde se registraron más de una treintena de agujeros destinados a alojar los postes de madera ${ }^{6}$, en ocasiones arriostrados con vigas, algunos de

\footnotetext{
${ }^{5}$ Analíticas realizadas en Roma durante el año 2002 por Artelab s.r.l.: Analisi microstratigrafiche e petrografiche finalizzate alla caratterizzazione de alcuni campione prelevati da pitture. Campione n. CC 3.

${ }^{6} \mathrm{Se}$ ha podido calcular una sección para estos postes de entre 30 y $40 \mathrm{~cm}$. Uno de estos agujeros conservaba en su fondo las huellas del pico utilizado para su apertura.
}

los cuales debieron pertenecer también a pies derechos internos destinados a soportar la carpintería de la cubier$\mathrm{ta}^{7}$. Su estructura portante requiere la existencia de elementales armaduras de pares (en ocasiones dispuestos radialmente), extendidos desde las vigas cumbreras hasta las paredes, que servirían de soporte a los ramajes vegetales de la techumbre (Figura 6).

Este tipo de estructuras sufrió múltiples labores de recambio y mantenimiento que el registro arqueológico documenta principalmente en forma de agujeros cortados sucesivamente entre sí, en ocasiones hasta tres veces. Aunque la casuística es grande, uno de los ejemplos más habituales es la característica forma de 8, que refleja un primer agujero cortado por un segundo en posición ligeramente corrida.

La ausencia de clavos de hierro denuncia la construcción de estructuras ensambladas sin ayuda de piezas metálicas de fijación, recurriéndose en su lugar a diversas técnicas alternativas. El sistema más elemental consistió probablemente en el empleo de horquillas portantes, obtenidas de forma natural en la madera o bien talladas artificialmente. Otros sistemas más evolucionados que también debieron usarse, y que requieren de mayor trabajo y precisión, fueron el ensamble a media madera, utilizado tanto para ensamblajes perpendiculares como oblicuos, y el denominado a caja y espiga, usado principalmente para uniones en ángulo recto. Estas dos últimas técnicas presentan la virtud de no desunirse por efecto de tensiones o empujes ejercidos desde el plano de las dos piezas ensambladas, por lo que son especialmente indicadas para estructuras de gran porte y complejidad.

Otro tipo de edificios más elementales con suelos de madera en suspensión fueron los graneros. En la primera de las fases detectadas en la primitiva Gasteiz (700-850 d.C.) se ha podido reconocer una de estas estructuras de almacenamiento, constituida por un mínimo de siete pilares, sobre los cuales debía de montarse la estructura portante (A4). El destacado diámetro y profundidad de los agujeros de poste, la escasa separación existente entre ellos y su disposición en ángulo son rasgos característicos de este tipo de edificios (Figura 8).

- Con pavimento a nivel de suelo. Estamos ante otra de las principales variantes constructivas, utilizada en zonas llanas que no requieren de estructuras complejas que

\footnotetext{
7 Aunque la bibliografía recoge dos tipos principales de estructuras interiores para la cubierta (con una y con dos filas de postes siguiendo el eje axial del edificio; Chapelot, Fossier, 1980; Valenti, 2004), en nuestro caso resulta muy complicado reconocer este tipo de modelos arquitectónicos, debido a la aleatoria disposición interna de los agujeros de poste que no parecen seguir un eje regular.
} 


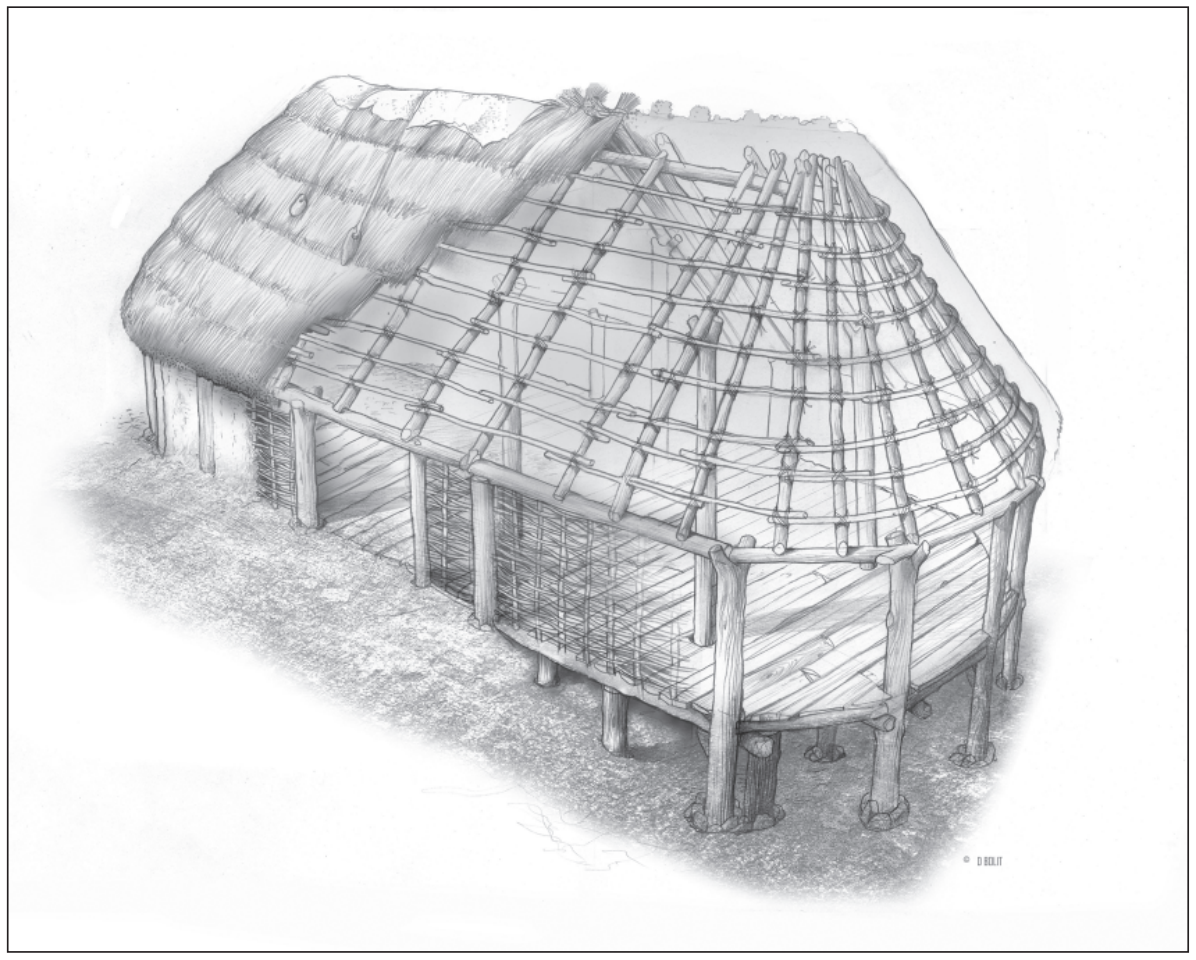

Fig. 6. Recreación de la estructura portante en la longhouse A1

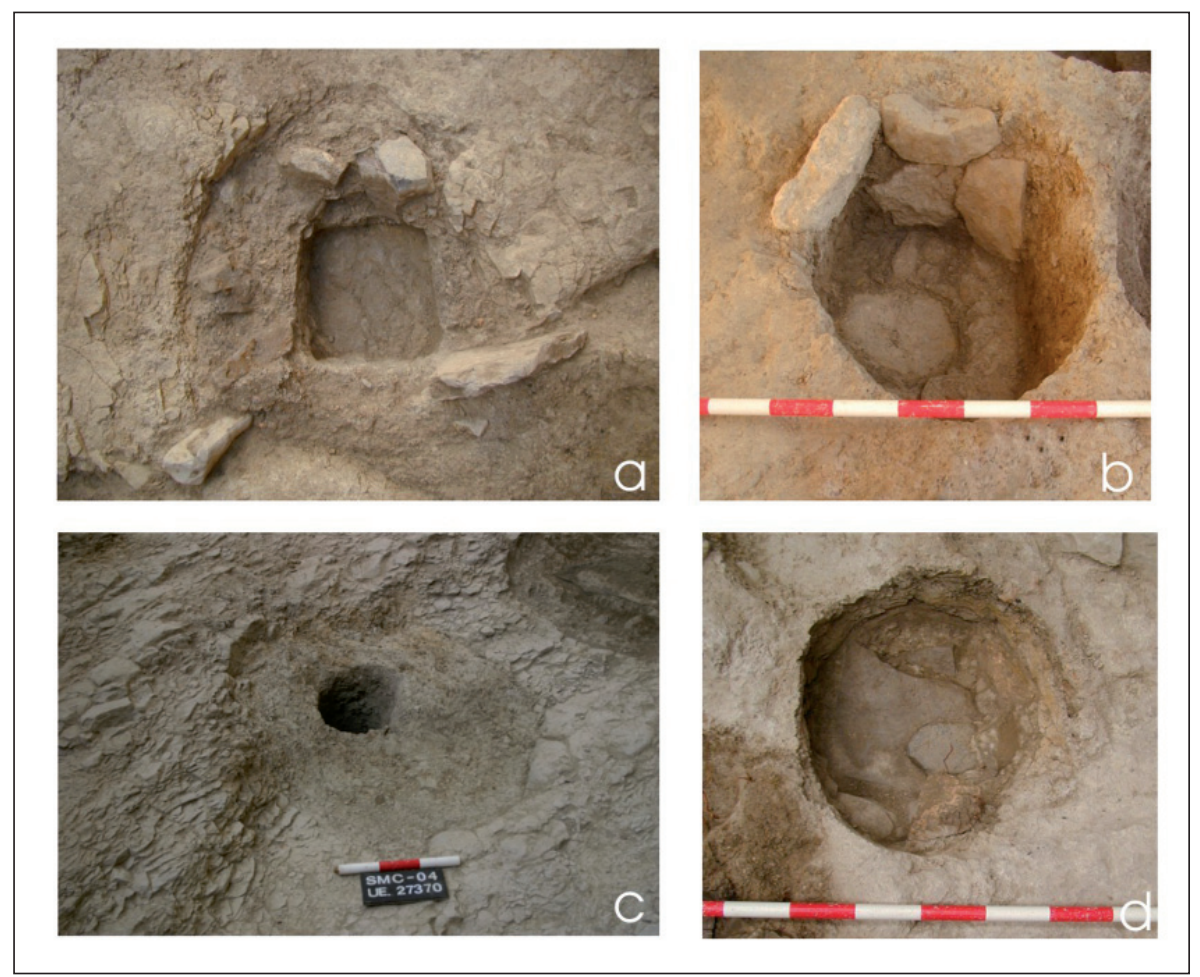

Fig. 7. Agujeros pertenecientes a las estructuras portantes de los diferentes edificios, con sus distintos tipos de fijación del poste (siglos VIII-X). El material utilizado para su sujeción fue preferentemente la arcilla; en ella quedaron registradas las improntas de los pies derechos, de sección cuadrangular (a) o circular (c). Más ocasionalmente, el poste estuvo fijado con calces de piedra (b), existiendo también ejemplos de piedras planas dispuestas en la base del agujero (d) 

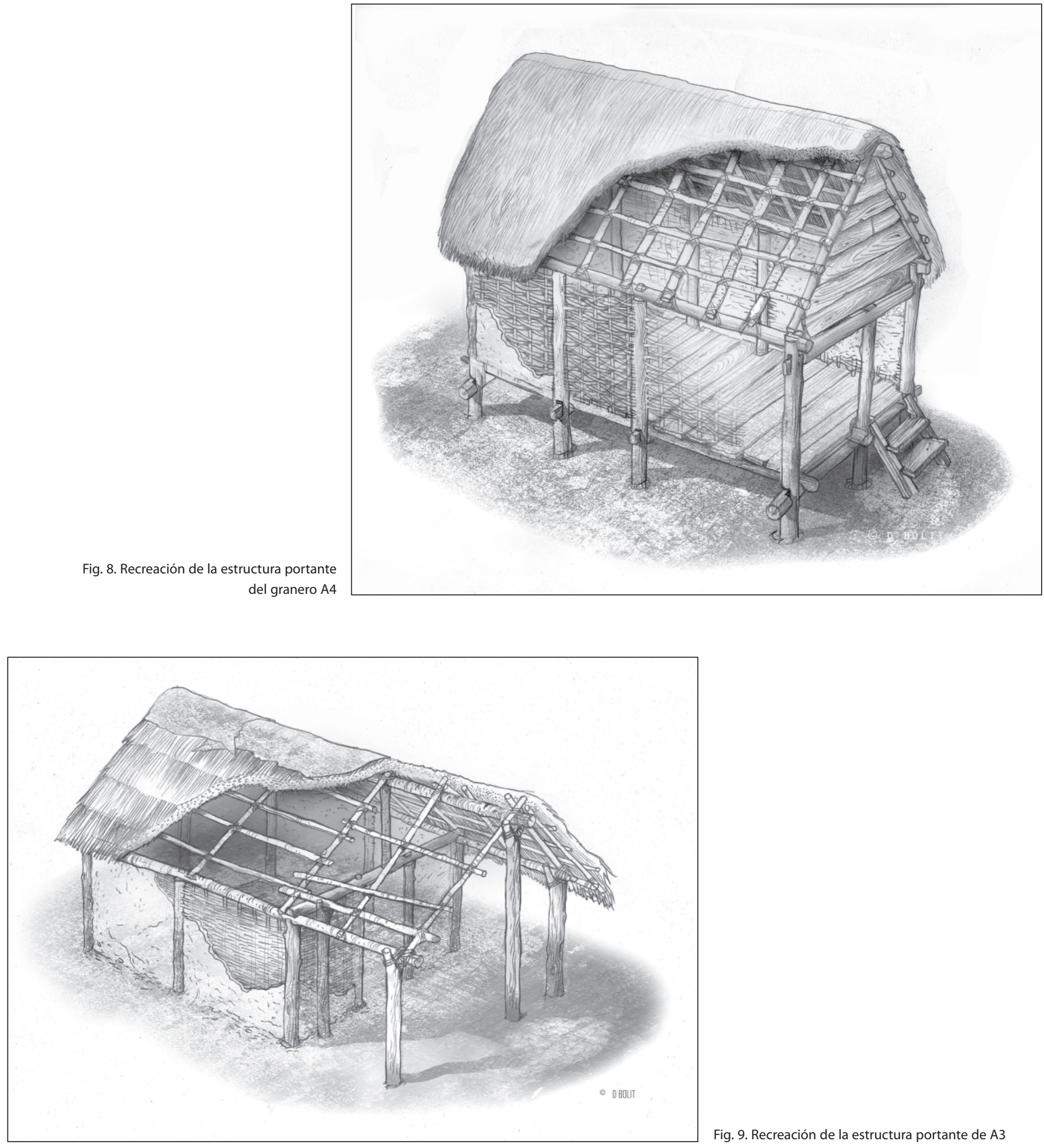

Fig. 9. Recreación de la estructura portante de A3

corrijan el desnivel del terreno. Esta variante, más fácil de ejecutar que la anterior, viene definida por el empleo de un convencional sistema de postes perimetrales embutidos en agujeros o rozas tallados en la roca y dispuestos a intervalos cortos (A3). La sencillez de este tipo constructivo explica su larga perduración en el tiempo (Figura 9).
- Con pavimento semiexcavado. Nueva variante constructiva cuyo suelo se sitúa al interior de un espacio excavado parcialmente en la roca. Se trata de una técnica minoritaria identificada en el edificio A5, de superficie próxima a los $20 \mathrm{~m}^{2}$, que parece asociarse con estructuras de almacén relacionadas a su vez con ambientes artesana- 


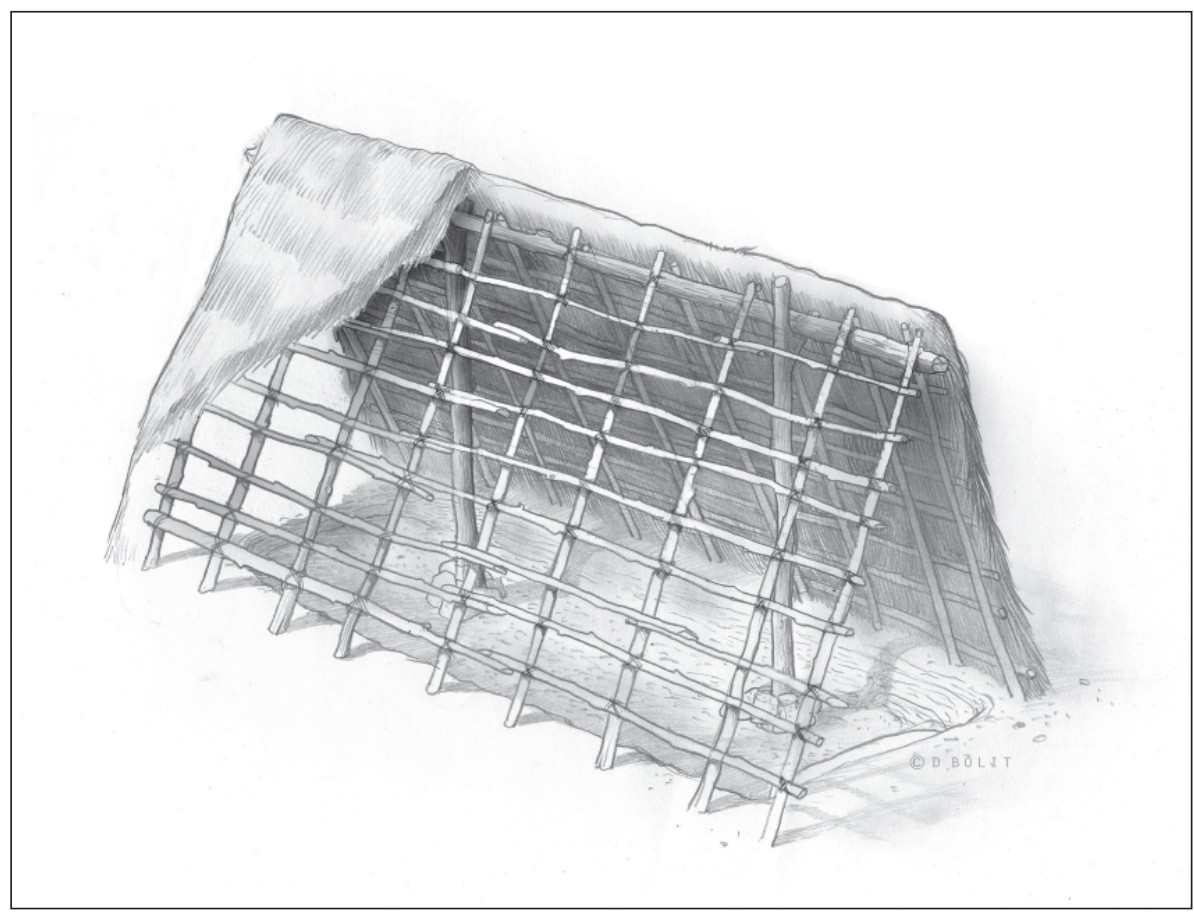

Fig. 10. Recreación de la estructura semiexcavada A5

les. La ausencia de postes tanto en el interior como en el perímetro externo de esta cabaña obliga a pensar en una estructura portante a nivel de suelo o, como muestra la figura 10, con la cubierta a dos aguas apoyada directamente en el terreno. Su existencia se documenta en Gasteiz entre los siglos VIII y IX.

La segunda estructura semiexcavada (A6) que se ha identificado en las excavaciones de Santa María no conservaba ningún tipo de suelo, ni se le puede asociar tampoco agujeros de poste al interior o exterior de la misma. La ausencia de estratos en el interior de esta cabaña y su ubicación en una zona de pendiente pronunciada podría denunciar la presencia de suelos de madera en suspensión cubriendo el rebaje ${ }^{8}$.

4.1.2. Zócalo de piedra. La introducción de la piedra como material de construcción a mediados del siglo $\mathrm{X}$ supuso un avance notable: por una parte porque los zócalos de piedra posibilitaban la deposición de potentes rellenos de arcilla que corregían el fuerte desnivel de la ladera y por otra porque, al apoyar sobre ellos el armazón de postes perimetrales, mejoraban tanto la durabilidad (en un clima húmedo y adverso) como la eficacia de las

\footnotetext{
${ }^{8}$ Aunque el registro arqueológico evidencia la existencia de fondos de cabaña y/ o rebajes en el terreno funcionando como suelos rehundidos de los propios edificios, son numerosos los casos interpretados en yacimientos ingleses donde se muestran también cubiertos por suelos de madera en suspensión (West, 1986, Tipper, 2000. Citado por H. Hamerow, 2002: 35; Tipper, 2004).
}

estructuras portantes que aminoraban la carga del muro a los puntos de apoyo de estos postes.

Identificados en el edificio residencial A57, estos zócalos presentan un aparejo de mampostería caliza margosa sin trabajar, de 0,6 $\mathrm{m}$ de grosor y apenas 0,4 $\mathrm{m}$ de altura, siguiendo hiladas más o menos horizontales (Figura 11). Se trata de estructuras construidas prácticamente en seco, sin ningún tipo de argamasa, aglutinadas mediante un pobre compuesto de arcilla enriquecida con pequeños puntos de cal. Para su asiento, especialmente en aquellas zonas con pronunciada pendiente, fueron necesarias zanjas de cimentación en las que se depositaron niveles arcillosos que servían de base al muro y proporcionaban mayor estabilidad a la estructura portante.

Las innovaciones técnicas alcanzaron también a la estructura portante de la cubierta, al ubicarse los postes en los zócalos perimetrales y crear, de esta forma, un espacio interior despejado. Ello exigía, obviamente, una cubierta a dos aguas con armadura de parhilera, con los pares arrancando de un tirante debidamente encastrado en las vigas carreras. Cada cercha pudo estar reforzada, además, por un pendolón y dos tornapuntas (Figura 12).

4.1.3. Técnica mixta. Las estructuras portantes en técnica mixta se caracterizan por el uso conjunto de zócalos (de piedra o madera) y armaduras de postes directamente embutidos en el terreno. El empleo de ambos elementos portantes debió proyectarse desde la fase inicial de cons- 
Fig. 11. Zócalo de piedra perteneciente al cierre septentrional del edificio A57. Obsérvese, detrás de él, el suelo de arcilla de la estancia y restos de un hogar a su izquierda
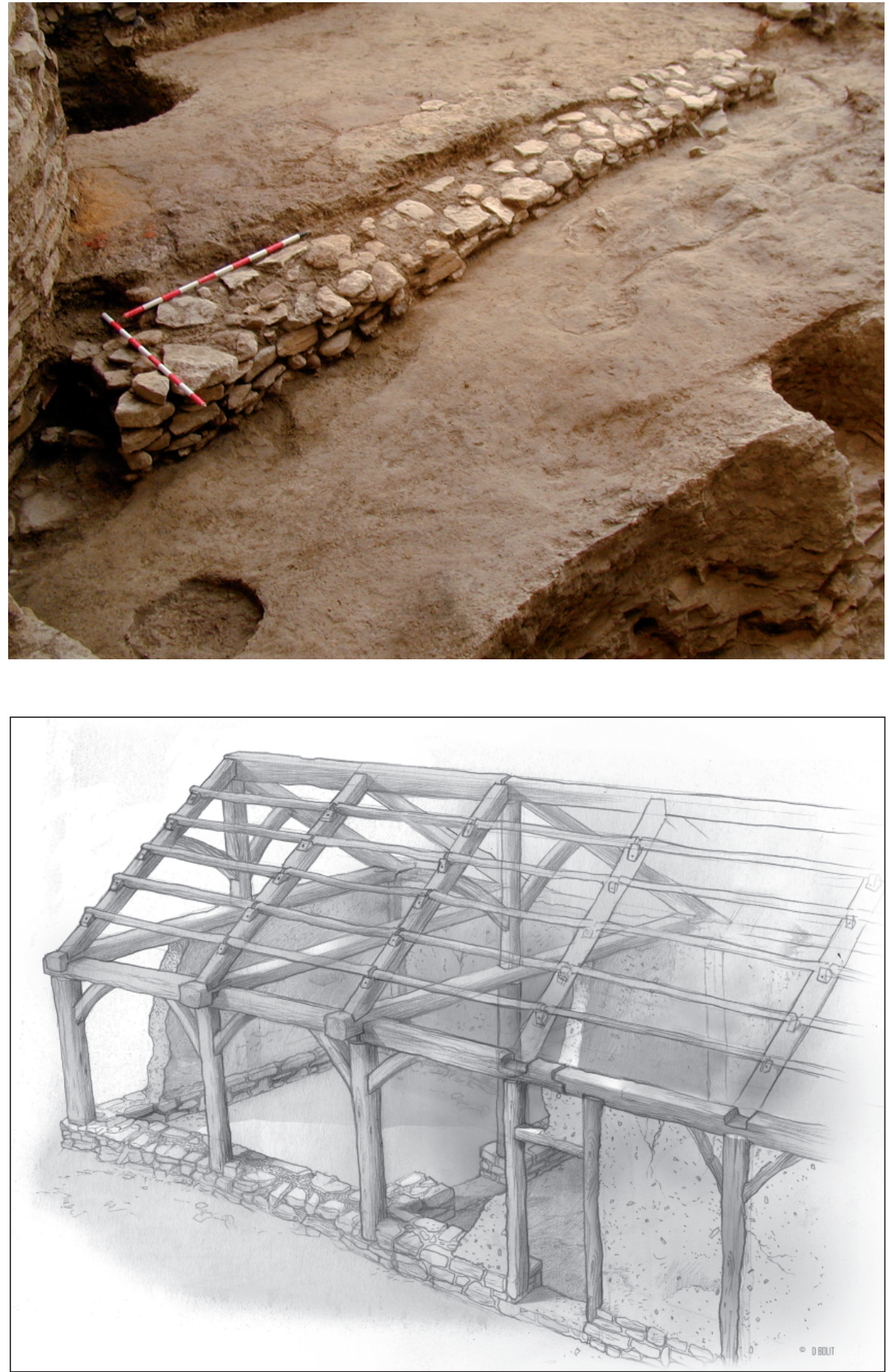

del edificio A57

trucción o, en todo caso, como consecuencia de una reestructuración sustancial del edificio, pero nunca como resultado de acciones puntuales (Fronza, 2008) ${ }^{9}$.

\footnotetext{
${ }^{9}$ Aunque casi todas las estructuras sobre zócalos de piedra registran la presencia de postes en el terreno, estos suelen ser completamente ocasionales y generalmente imputables a refuerzos instalados durante la vida de los edificios. En el caso de las estructuras en técnica mixta, en cambio, la presencia de la armadura de postes es consecuencia de una precisa estrategia constructiva (Fronza, 2008).
}

En las excavaciones de la catedral Santa María podemos observar dos variantes de esta técnica si atendemos al diferente material empleado en la construcción de los zócalos, ambas documentadas en el siglo XI:

- Con basamento de piedra. Técnica registrada en el edificio A70 como resultado de la importante reforma acontecida en A57 (Figura 13). Esta reforma consistió, a grandes rasgos, en la construcción de tres nuevos zócalos 


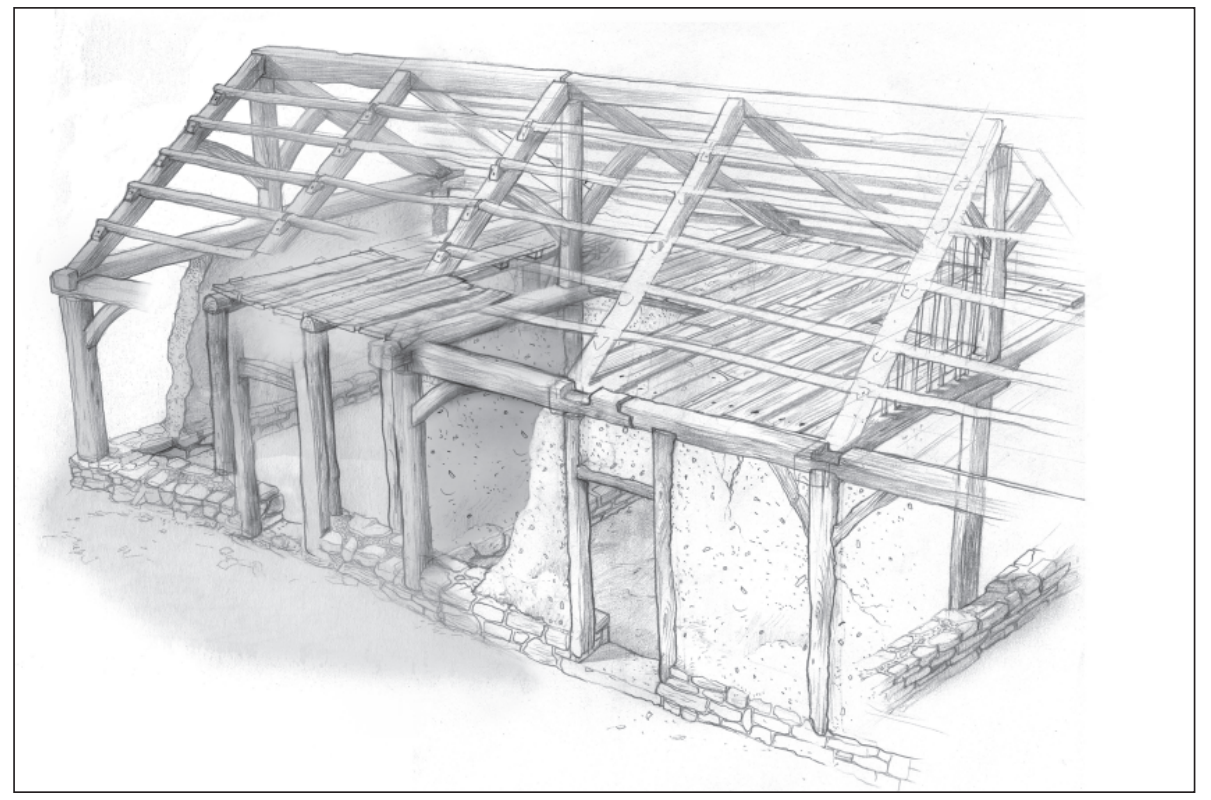

Fig. 13. Recreación de la estructura portante del edificio A70

de piedra al interior de A57 que, actuando como medianiles, dividieron el espacio interior en distintas estancias (A71, A72 y A73). Al mismo tiempo, en cada uno de estos ambientes se levantó un piso bajocubierta del que conservamos las improntas negativas de los postes que integraban su forjado. La técnica constructiva empleada utilizaba un sistema de tres parejas de postes embutidos directamente en el terreno y adosados a los muros este y oeste, donde apear tres jácenas que soportaban a su vez las viguetas transversales del piso superior. En una de las estancias, la estructura se reforzaba además por una viga transversal norte-sur.
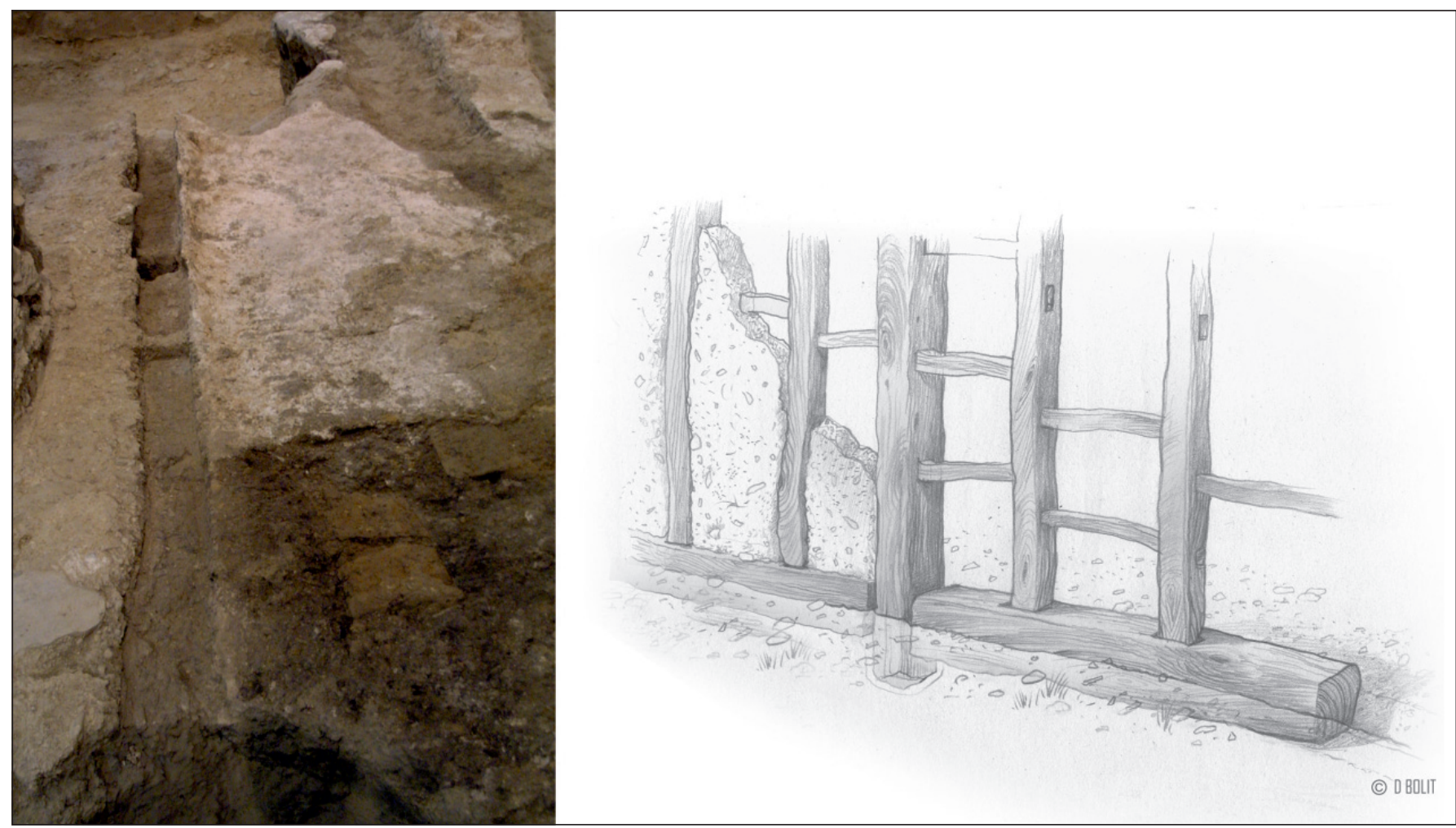

Fig. 14. A la izquierda, impronta de varios durmientes de madera pertenecientes a un edificio exhumado en la catedral de Santa María (A77), donde se observa también el agujero de poste de un pie derecho intermedio. A la derecha, reconstrucción de su estructura portante sobre postes y zócalos de madera 
Fig. 15. Recreación de la estructura portante del edificio A83

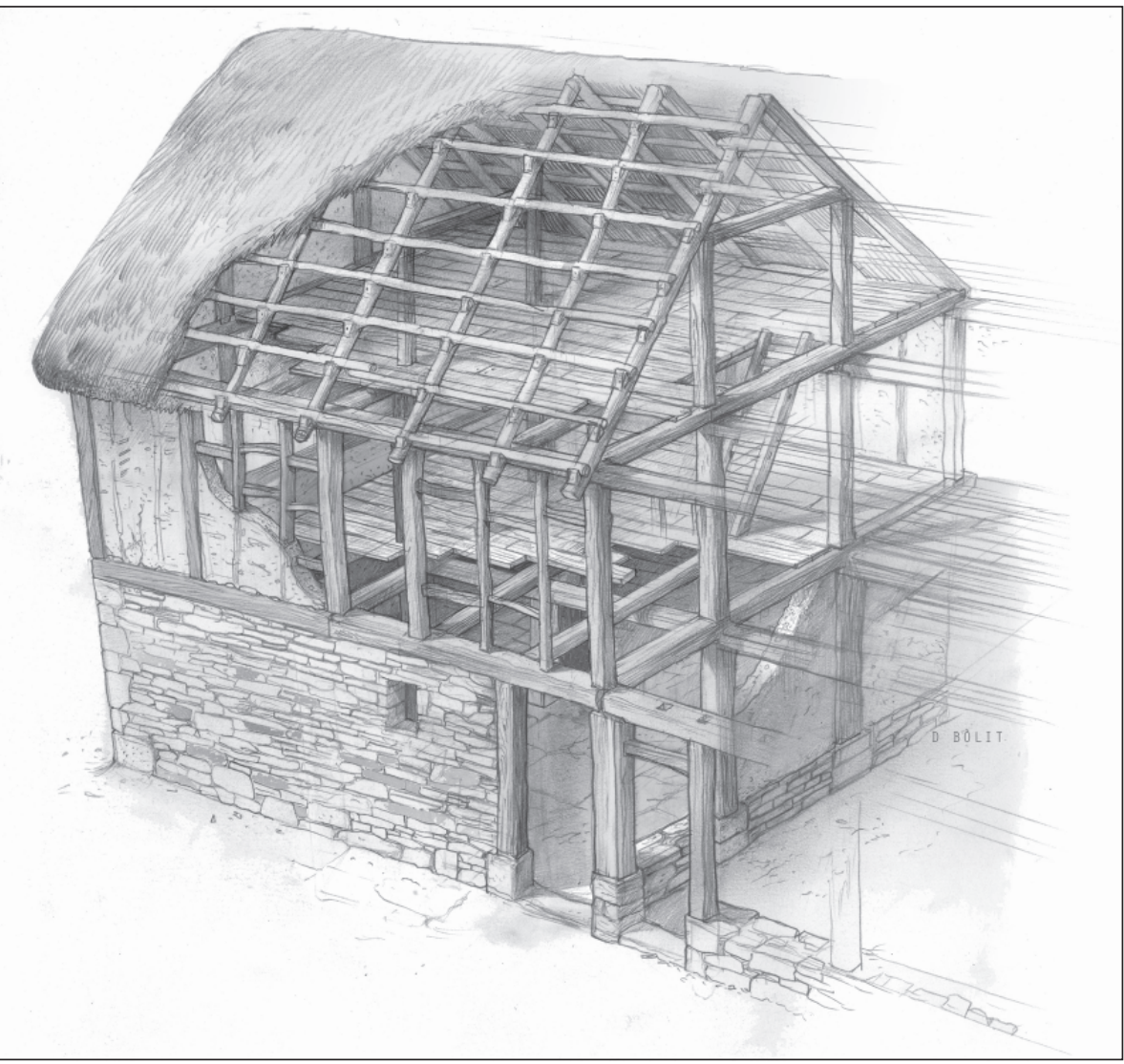

- Con basamento de madera. Nueva variante caracterizada por durmientes lígneos, jalonados a intervalos regulares por pies derechos sobre los que se articularon los alzados de carpintería. Las trazas de estos durmientes quedaron perfectamente reflejadas en el registro estratigráfico en forma de surcos abiertos en el suelo, algunos de los cuales aún conservaban restos de madera. Con una longitud de $1,2 \mathrm{~m}$. y una sección rectangular de entre 15 y 18 $\mathrm{cm}$. de grosor (Figura 14), su utilización, en cualquier caso, parece que fue muy limitada, documentándose en una única estructura datada en el siglo XI (A77).

4.1.4. Muros de piedra. Los primitivos zócalos de piedra empezarán a ser sustituidos a partir del siglo XII por muros levantados a lo alto de toda o buena parte del piso inferior de los edificios. La gran estructura A83, compuesta por un mínimo de cuatro casas contiguas, es un buen ejemplo de esta nueva técnica (Figura 15). Su principal diferencia respecto a los anteriores basamentos pétreos radica, más allá de la altura, en que estos nuevos funcionaban como verdaderos muros de carga. Morfológicamente se trata de construcciones de doble hoja con núcleo incastrato ${ }^{10}$, de un gro-

${ }^{10}$ Cfr. Fiorani, 1996: 163. sor de $c a .0,65 \mathrm{~m}$, aparejados en hiladas más o menos regulares con bloques de calcarenita regularizados por un desbastado previo.

Los medianiles de cada casa se construyeron sobre zócalos de piedra en los que se intestaron dos grandes basas, muy sólidas y compuestas por bloques calizos superpuestos, que sirvieron para el apeo de sendos pies derechos. Esta circunstancia revela la existencia de un gran armazón lígneo transmitiendo importantes cargas: una crujía central de madera pensada para ser más alta que los muros perimetrales de cierre y, de este modo, ganar altura con un nuevo piso.

En lo que atañe a la cubierta, no parece modificar mucho su aspecto respecto a la observada en el edificio A57, pudiendo mantener una armadura de parhilera o de par y nudillo, aunque con las vertientes más tendidas y desarrolladas de cara a alojar una crujía central superior. El material para la techumbre tampoco debía diferenciarse mucho del propuesto anteriormente (ramajes vegetales).

\subsection{Cierres}

Llamamos cierres a aquellas estructuras que delimitan los edificios en su perímetro exterior e interior, pudiendo funcionar como muros de carga sobre los que apoyar 


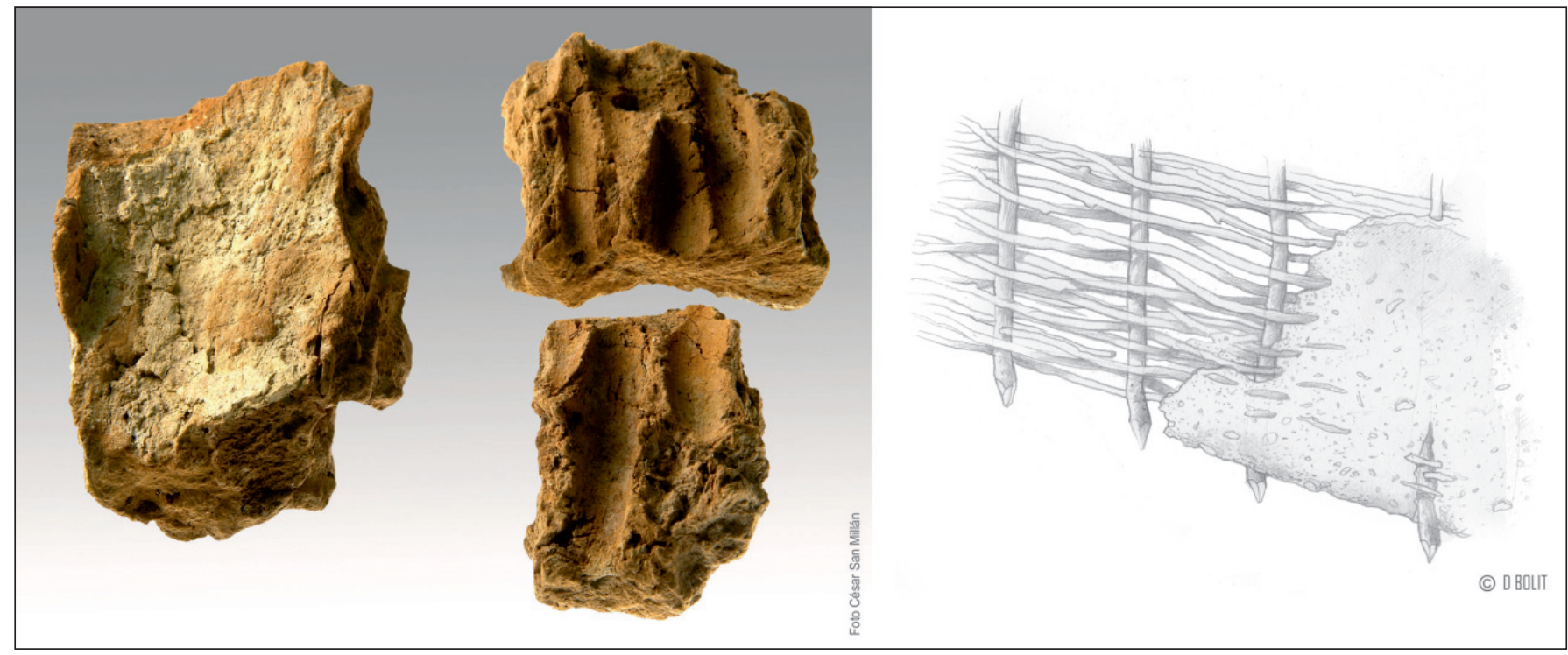

Fig. 16. A la izquierda, fragmentos de revestimiento de barro empleados en el clayonnage o torchis. A la derecha, recreación de esta técnica constructiva

forjados o como simples paredes de cierre sin función estructural. Las técnicas identificadas en la primitiva Gasteiz para su construcción fueron las siguientes:

4.2.1. Clayonnage o intreccio. La presencia, en el registro arqueológico, de numerosos testimonios de barro con improntas vegetales denuncia el empleo sistemático del clayonnage, técnica mediante la cual se construye un esqueleto de zarzos tejido de ramas entrelazadas y posteriormente manteado con arcilla cruda tanto al interior como al exterior (Figura 16). Su rapidez y sencillez en la ejecución, así como la posibilidad de levantar el armazón y cubierta del edificio sin necesidad de realizar antes los muros (quedando rápidamente al abrigo de la lluvia) son algunas de las ventajas que ofrece esta técnica. Como principales inconvenientes han de mencionarse la fragilidad del conjunto, su escasa durabilidad, el riesgo alto de incendio y la necesidad de enlucir las paredes exteriores para protegerlas de las inclemencias meteorológicas (Bardou, Arzoumanian, 1979: 22).

Aunque constituye el principal sistema de cierre en los edificios con estructura portante de armadura de postes (siglos VIII-X), se trata de una técnica con una amplia difusión cronológica, identificable en todos los periodos estudiados.

4.2.2. Stabbau. Es, junto al clayonnage, una de las principales técnicas utilizadas para el cierre de las paredes en los edificios de época altomedieval. En Gasteiz, la documentación de varias zanjas o canaletas perimetrales en algunas estructuras (A2 y A34) confirma también su uso (Figura 17). Se trata de un sistema que recurre al uso de troncos o semi-troncos verticales embutidos en el interior de las zanjas (calzados con tierra o piedras) que, con frecuencia, suelen estar intercalados por pies derechos de mayor porte pertenecientes a la propia estructura portante del edificio. Esta es, sin duda, una de las formas más primitivas de stabbau o mur-palissade, (Chapelot, Fossier, 1980).

4.2.3. Façonnage direct sobre zócalo de piedra. La aparición de los zócalos de piedra trajo consigo la incorporación de una nueva técnica para los alzados que la bibliografía francesa denomina bauge o façonnage direct (Chazelles-Gazzal, 1997: 19ss). Esta técnica mixta está basada en la disposición de pellas de barro modeladas manualmente y colocadas sucesivamente en varios niveles sobre el zócalo de mampostería, donde la cohesión y la resistencia se obtendrían por desecación (Figura 18). Aunque puede llegar a confundirse con otras técnicas de tierra, sus construcciones se diferencian por su aspecto uniforme, sin marcas de improntas vegetales como en el clayonnage, juntas de trabazón como el adobe o marcas de encofrado como el tapial (Sánchez García, 1999).

Las ventajas de este nuevo sistema constructivo son muchas, principalmente referidas a la durabilidad y consistencia de la estructura, ya que el zócalo de piedra evita la humedad por capilaridad. Presenta además un excelente aislamiento térmico cuando la pared es de espesor grueso y una buena resistencia a los incendios. Por contra, y a 


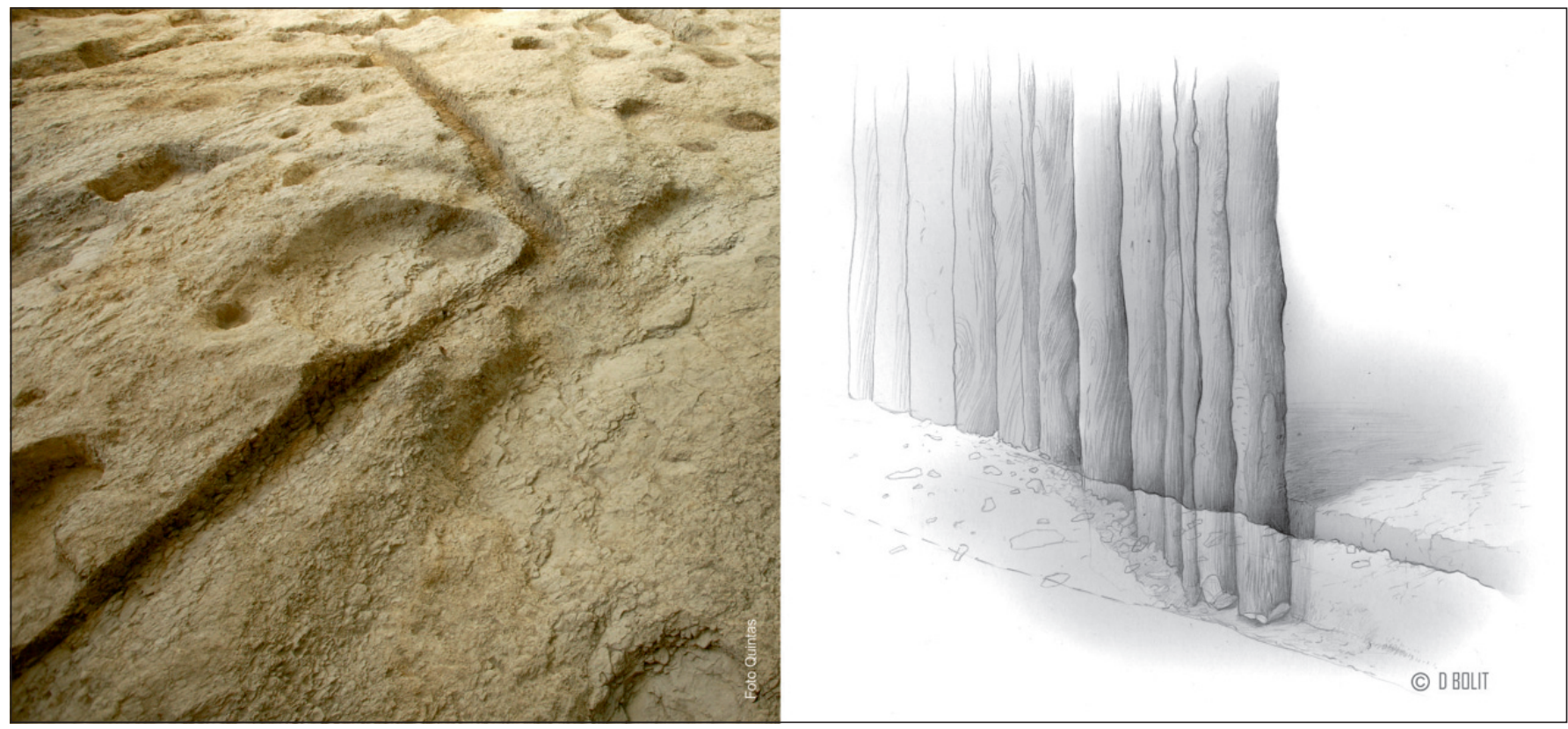

Fig. 17. A la izquierda, trazas visibles de la zanja perimetral de la estructura A34. A la derecha, recreación de la técnica constructiva en stabbau

Fig. 18. Restos conservados de façonnage direct sobre zócalo de piedra

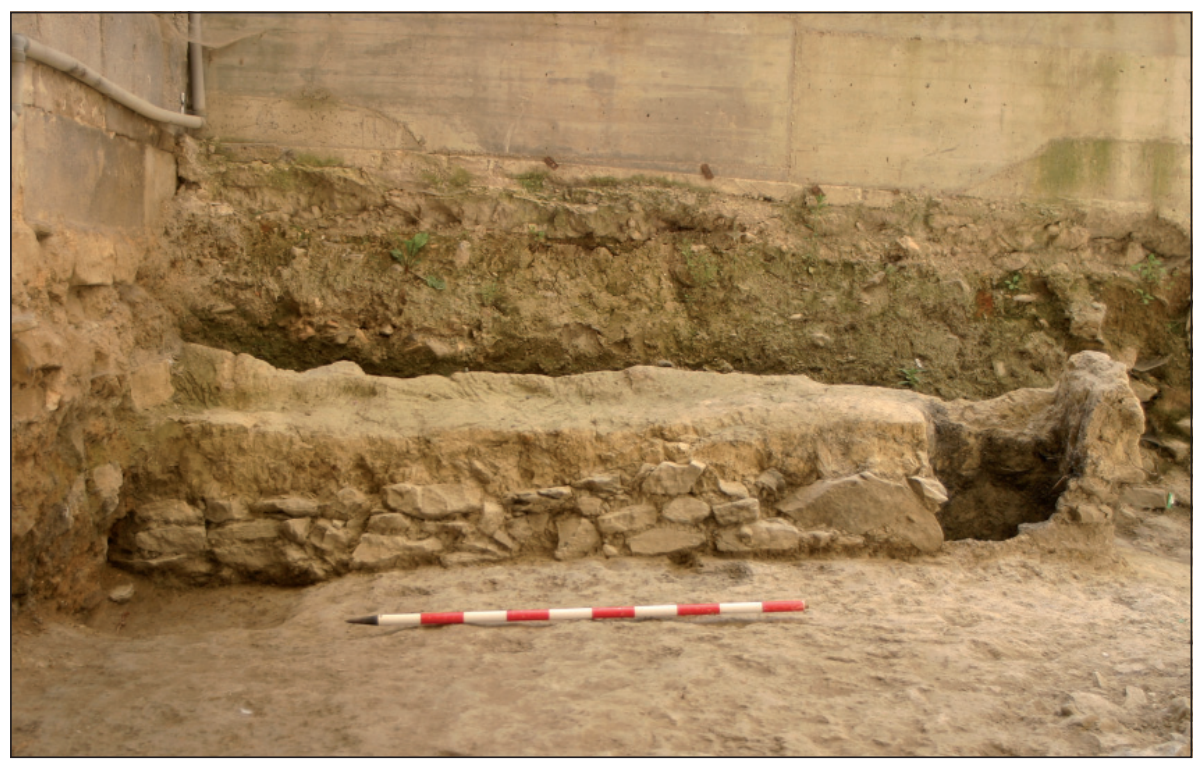

diferencia de la técnica constructiva asociada al clayonnage, exige una cierta especialización en la mano de obra, un largo periodo de secado y la construcción de los muros de cierre antes de levantar el armazón del tejado, ya que en el façonnage direct la arcilla efectúa una función estructural. Por otra parte, y como todas las técnicas constructivas con barro, resiste mal la erosión del agua o el viento, por lo que la pared necesita ser enlucida (Bardou, Arzoumanian, 1979: 29; Sánchez García, 1999: 167ss).

4.2.4. Adobe. A diferencia de las técnicas precedentes, el adobe sólo se registra en Gasteiz como parte del equipamiento doméstico de la casa (como pared de aislamiento de algunos hogares), sin que hasta el momento haya podido reconocerse su uso como cierre de paredes perimetrales. Hay que suponer, no obstante, un uso más generalizado que el que registra la documentación arqueológica, máxima si tenemos en cuenta que su uso está bien constatado en otros asentamientos cercanos como Zaballa (Alfaro, 2012) y que algunas técnicas constructivas como el pan de bois necesitan de materiales de relleno como el adobe.

El ejemplo mejor conservado se localizó en la vivienda $\mathrm{A} 72$, en cuyo interior un pequeño murete de adobes 
Fig. 19. Hogar registrado en la vivienda A72. Obsérvese, a su izquierda, el murete de separación construido con adobes

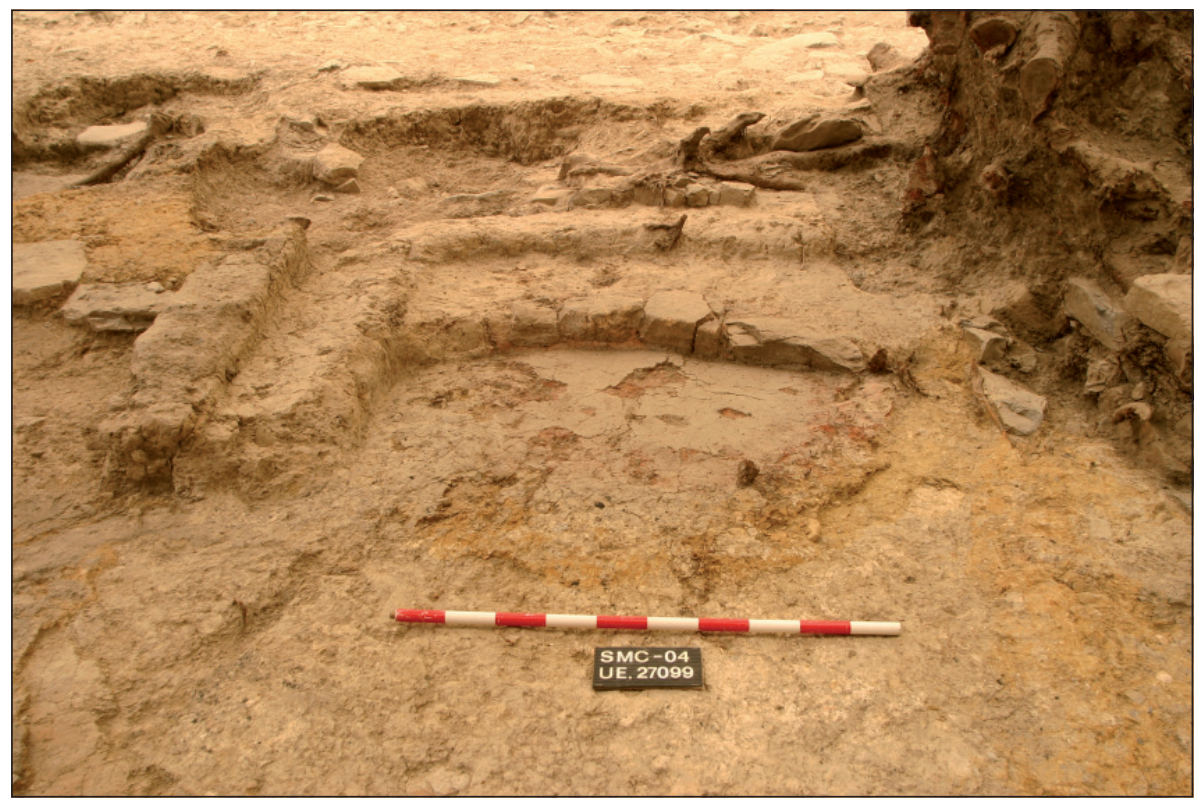

separaba el hogar de la puerta de acceso (Figura 19). Conservaba un mínimo de tres hiladas construidas por adobes de módulo rectangular o cuadrangular $(c a .30 \mathrm{~cm}$. de longitud $\times 25 \mathrm{~cm}$. de anchura $\times 10 \mathrm{~cm}$. de altura) dispuestos a soga y elaborados con una mezcla de arcilla, arena, pequeños puntos de cal y carbones (composición muy similar, por otra parte, a la tierra empleada para la trabazón de los propios adobes, lo que dificultaba notablemente la identificación de algunas juntas de unión.

Las ventajas de este material radican en que, una vez secos los adobes, su puesta en obra resulta muy simple y rápida. Frente al tapial requiere, además, menos mano de obra y se adapta a todo tipo de formas constructivas: bóvedas, viviendas circulares, rellenos de entramados, etc. Sus principales inconvenientes derivan del proceso de fabricación previo al poder presentar, por la contracción en el secado, fisuras que afectan a la estabilidad de la construcción (Sánchez García, 1999: 176).

4.2.5. Pan de bois o fachwerk. Aunque el pan de bois es una técnica bien conocida en la arquitectura medieval a través de la iconografía, los textos y algunos restos materiales en edificios tardomedievales (Chazelles-Gazzal, 1997: 206), resulta muy complicada de detectar arqueológicamente al carecer los muros exhumados de huellas o improntas que acrediten esta técnica (un hecho que hace difícil, a su vez, fijar una fecha concreta para su introducción). En nuestro caso, el registro arqueológico de zócalos de madera permite, cuando menos, plantear la hipótesis lógica de su empleo en el siglo XI, si bien no será hasta los siglos XII-XIII cuando empiece a generalizarse su uso, asociado a la elevación en altura de la casa y a la necesidad de aligerar el grosor y peso de los cierres superiores.

Esta técnica se puede relacionar con el opus craticium de Vitruvio (De Arch. II, 1, 3, 8), lo que la distinguiría respecto a otras técnicas más rústicas de carpintería que, como el clayonnage, son tratadas por éste y otros autores clásicos de manera peyorativa (Chazelles-Gazzal, 1997: 129). En efecto, este sistema se distingue por presentar un armazón de postes verticales y codales horizontales encajados, que genera sólidos paneles cuadrados o rectangulares rellenados por arcilla, adobes o ladrillos (Figura 20). Esta técnica requiere a menudo de una preparación muy compleja del maderamen en el taller del carpintero para su

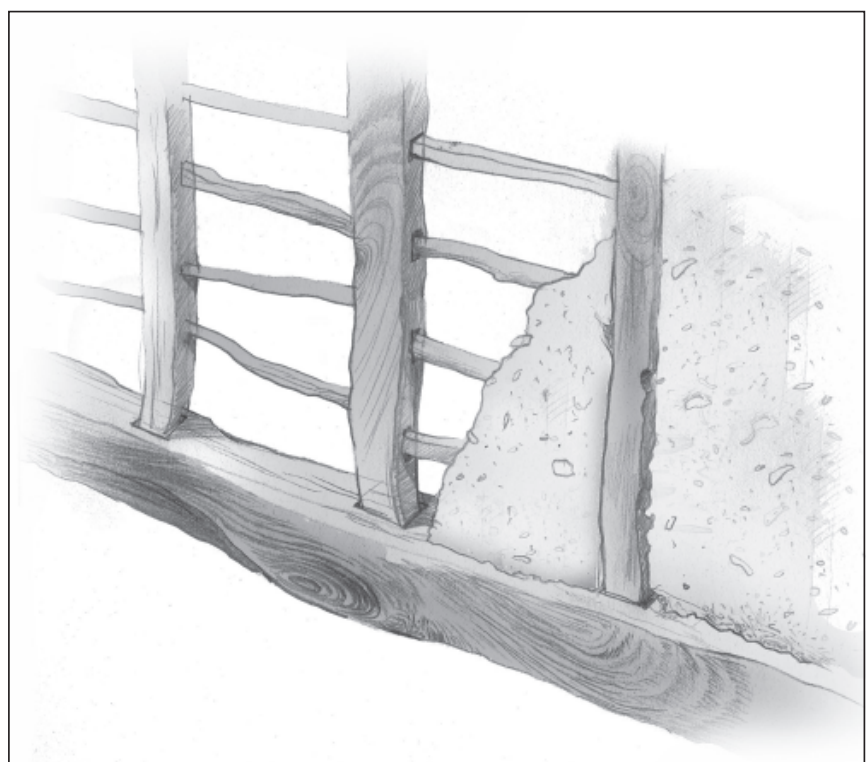

Fig. 20. Recreación de la técnica constructiva del pans de bois 
Fig. 21. Suelo de tierra y hogares registrados en la fragua A71. En primer plano puede verse el nivel de preparación de un hogar a base de cantos de río y lajas, sobre el que se conserva parte de la capa de arcilla decantada de color amarillento. Al fondo, un segundo hogar con la arcilla rubificada por efecto del fuego

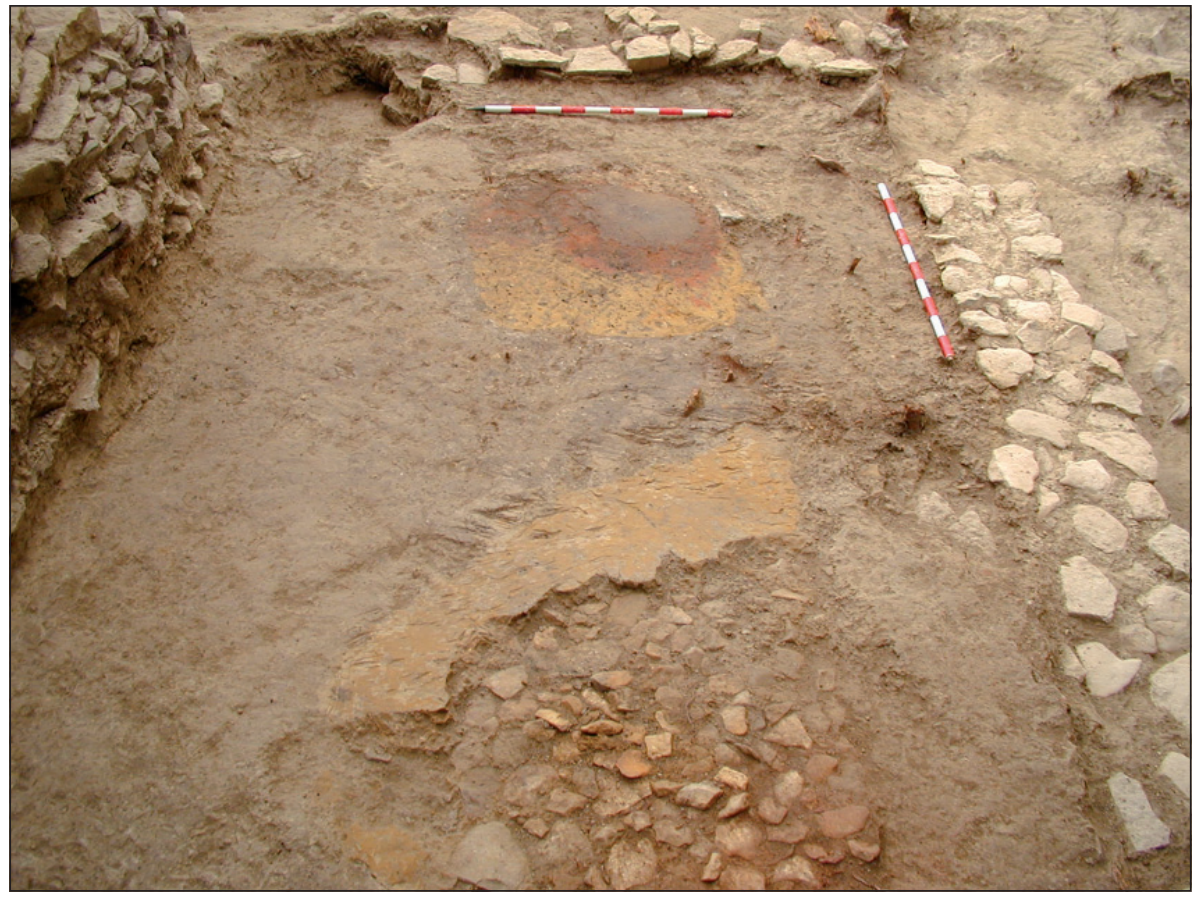

posterior montaje en el edificio, pudiéndose estimar una relativa estandarización de los tipos de estructuras, de los modos de ensamblaje y de los módulos (Chapelot, Fossier, 1980: 262).

\subsection{Suelos}

Este último capítulo reúne los diferentes tipos de pavimentos detectados al interior de los edificios, ya que, como apunta Fronza (2008: 278), i piani d'uso interni alla struttura forniscono dati di un certo interesse per definire la qualità della tecnica costruttiva e gli aspetti funzionali di un edificio. En nuestro caso, se han detectado tres tipos de suelos atendiendo al material empleado en su construcción:

4.3.1. Suelos de madera. Desde un principio expresamos nuestra sorpresa por la casi total ausencia de suelos en los primeros edificios documentados en Gasteiz ${ }^{11}$, una circunstancia que atribuíamos inicialmente a las escorrentías típicas de un terreno en ladera que, durante periodos de abandono, lavaron literalmente una zona de muy poca potencia edáfica (Azkarate, 2007). Sin ser totalmente equivocada esta afirmación, a día de hoy sabemos que su ausencia debe explicarse más por el uso generalizado de pisos suspendidos de madera que por razones postdeposicionales. Como señalábamos más arriba al describir las

\footnotetext{
${ }^{11}$ La única excepción se corresponde con la estructura semiexcavada A5, en cuyo interior se documentaron suelos de arcilla batida.
}

estructuras portantes, la utilización de complejos armazones verticales de madera facilitó la construcción de suelos lígneos en suspensión (difíciles de detectar arqueológicamente por no dejar ningún tipo de huella en el terreno, más allá de los agujeros de los propios pies derechos). Su uso, extendido entre los siglos VIII y X, permitió obtener un suelo confortable sin alterar la orografía del cerro y un correcto aislamiento del terreno, evitando humedades por capilaridad.

4.3.2. Suelos de tierra batida. La incorporación de los zócalos de piedra a la arquitectura doméstica de Gasteiz (mediados del siglo X d.C.) coincidió con la modificación de la orografía del lugar mediante el recurso a grandes nivelaciones y aterrazamientos que lograron la explanación de la ladera facilitando su posterior reurbanización. Todo ello facilitó, sin duda, la construcción de suelos de tierra, generalmente de arcilla batida y apisonada, en ocasiones muy limpia, con un espesor variable entre los 10 y $20 \mathrm{~cm}$.

La presencia de estos pisos facilitó a su vez el registro «in situ» de hogares bajos que, atendiendo a su factura, pueden dividirse en dos tipos: el primero, menos representado aunque más sencillo de ejecutar, se conformaba con un manteado de arcilla extendido directamente sobre el suelo; el segundo ofrecía una técnica algo más elaborada, al mostrar una preparación térmica previa, compuesta por cantos de río en unos casos y por lajas caliza en otros, sobre la que se extendía una capa de arcilla decantada (Figura 
21). En este segundo modelo, el fuego se aislaba frecuentemente con un resalta perimetral de piedra o arcilla.

4.3.3. Suelos de yeso y cal. Una de las soluciones adoptadas para evitar o limitar la humedad y los procesos de deformación de los suelos fue la utilización de una compacta capa de yeso o cal mezclada con paja, fuertemente apisonada.

Todo apunta, sin embargo, a que se trata de un tipo de pavimento bastante excepcional ya que se documenta en un único edificio datado en el siglo XI (A77), asociado a un tipo concreto de estructura portante en técnica mixta sobre zócalos de madera (Figura 14).

\section{CONSIDERACIONES FINALES}

1. La más antigua unidad doméstica exhumada en el extremo septentrional de Gasteiz muestra un patrón espacial que hemos venido a llamar "desagregado» y que se caracteriza por la presencia exclusiva de edificios con armaduras de postes y alzados de clayonnage o stabbau, acompañados ocasionalmente por algunas estructuras semiexcavadas (grubenhaus).

Tal y como hemos visto, la madera y el barro fueron los materiales utilizados mayoritariamente en la primitiva Gasteiz. Los análisis de captación del material lígneo muestran una selección discriminada en función de su destino, lo que implica a su vez un conocimiento de sus propiedades. El roble, de fácil adquisición en masas forestales no demasiado alejadas, fue utilizado en la construcción de las estructuras portantes. El haya, en cambio, con fuentes de aprovisionamiento más apartadas, es minoritario según los análisis antracológicos. Parece, en consecuencia, que la facilidad de acceso a los materiales favoreció lógicamente su uso preferente.

Otro tanto cabe deducir del uso de las arcillas: la extracción del barro empleado el manteado de los zarzos con los que se levantaron las paredes de cierre (clayonnage) se realizó en el mismo asentamiento, dentro incluso de los límites de la propia unidad doméstica, como demuestra la aparición de un barrero de aproximadamente 80 metros cuadrados de superficie, cuya actividad se mantuvo constante entre los siglos VIII y IX d.C.

El recurso sistemático a los materiales del entorno inmediato, el empleo de técnicas constructivas poco sofisticadas y la escasa inversión de energía empleada explica que la mayoría de estructuras fueran levantadas de manera rápida y eficaz, en muy poco tiempo y sin necesidad de una mano de obra especializada, y esclarece también el elevado índice de recambio que requiere esta arquitectura efímera ${ }^{12}$. Se debe de pensar, en consecuencia, en una arquitectura realizada mayoritariamente por los propios habitantes de la unidad doméstica, sin la intervención de personal especializado $y$, por tanto, sin signos aparentes de iniciativas señoriales. Sólo la construcción de una longhouse a mediados del siglo IX permite percibir algunos signos de jerarquización social, circunstancia que se hará mucho más evidente años más tarde.

2. Los años centrales del siglo $X$ suponen un punto de inflexión en los modos constructivos de la unidad doméstica al constatarse, por primera vez, el empleo de zócalos de piedra en las estructuras portantes de los principales edificios. El cambio coincide con el momento en que la vieja unidad adopta una morfología más racional y agrupada que derivará en la aparición de un espacio abierto central de límites más precisos que en el periodo anterior (casa con patio), un esquema que recuerda algunos procesos de agregación espacial bien documentados en contextos del sur peninsular (Gutiérrez Lloret, Cañavate, 2010).

Las dimensiones de la vivienda (A57) en esta nueva fase son espectaculares para la época y, por sí mismas, ya denuncian la relevancia del lugar, de sus propietarios y, en general, de la operación urbanística que condujo a esta profunda transformación. Un dato que, unido a la modificación de la orografía del lugar mediante el recurso a grandes nivelaciones de tierra, obliga a pensar en instancias de poder con capacidad suficiente para liderar e imponer operaciones de esta naturaleza.

El recurso a los zócalos de piedra se complementa con alzados de barro amasado (façonnage direct) que, a diferencia del tradicional clayonnage, exigen una cierta especialización en la mano de obra. No se observa, sin embargo, una conducta selectiva en la obtención de la piedra ni una técnica cuidada, al emplearse exclusivamente margas calizas extraídas del propio substrato rocoso de la colina, a pie de obra, apenas desbastadas y aparejadas de manera irregular sin argamasa. Tampoco creemos que fuese preciso. Aunque esta roca suele presentar problemas de desintegración y resistencia mecánica, su utilización puede conside-

\footnotetext{
12 Como apuntábamos en otro lugar (Azkarate, 2007), existen numerosos agujeros de poste cuya función nunca sabremos con total certeza: unas veces responderán a pequeñas estructuras auxiliares, otras veces a replanteos parciales; unos serán reflejo de sucesivas compartimentaciones interiores, otros serán consecuencia de sustituciones de pies sustituciones y otras acciones constructivas que coadyuvaran al mantenimiento de unas estructuras de naturaleza derechos deteriorados. Todos ellos responderán, en definitiva, a una casuística interminable derivada de la vida misma en una aldea campesina autosuficiente. No olvidemos que un poste hincado directamente en el suelo tenía una tasa de recambio generacional, y que, por fuerza, tuvieron que existir numerosos apeos, refuerzos.
} 
rarse apropiada, dadas las escasas cargas que transmiten los edificios construidos en estos momentos, valorándose más su cercanía y facilidad de extracción que otros aspectos mecánicos.

Estamos, en suma, ante una nueva etapa en la historia del lugar, caracterizada por la acentuación de determinados indicadores de poder. Como ha sido observado también en otros lugares (Ibidem: 125), la complejidad arquitectónica viene determinada no tanto por la técnica y morfología de los materiales empleados cuanto por la solución formal y adaptación al terreno, por el despliegue de medios dispuesto para generar aterrazamientos, construir márgenes de contención, por la capacidad, en definitiva, de alcanzar unos resultados que sólo cabe esperar de unas decisiones previamente planificadas y de una capacidad indiscutible para ejecutarlas.

Además, la presencia de soluciones constructivas comunes a otros asentamientos regionales (Bagoeta, Zaballa, Zornoztegi..., principalmente la introducción del zócalo de piedra) nos informa de unos conocimientos técnicos medianamente especializados, derivados bien del contacto entre los habitantes constructores, bien de cuadrillas de trabajadores llegados del entorno. Sea por contacto con otros ambientes técnicos o por la llegada de mano de obra, se puede observar ya la existencia de fenómenos de convergencia técnica, tanto a nivel formal (adopción mayoritaria de la planta rectangular en los edificios) como técnico (zócalos de piedra), que evidencian semejanzas culturales expresadas también en otros aspectos de la cultura material como la cerámica.

3. Al modelo de casa con patio le sucede durante los primeros años del siglo XI un modelo de casa unitaria, coincidiendo con el momento en que el urbanismo de Gasteiz se transforma radicalmente al incorporar una trama urbana organizada en calles. Son precisamente las nuevas necesidades impuestas por este entramado urbano las que provocarán la desaparición del modelo anterior y la adopción de un nuevo sistema de organización de las unidades domésticas en edificios multifuncionales alineados a ambos lados de las calles.

El proceso es más complejo si cabe, ya que la nueva casa surge como resultado de una profunda reforma acometida en el primitivo edificio residencial A57, en la que se documenta una nueva técnica mixta consistente en la utilización conjunta de zócalos de piedra y armaduras de postes embutidos directamente en el terreno. En algunos contextos europeos el uso de esta técnica mixta es interpretada, dentro del continuum evolutivo de las técnicas cons- tructivas, como un tipo intermedio entre las estructuras íntegramente de madera y los edificios con estructuras de piedra (Fronza, 2008). En nuestro caso, sin embargo, su registro se efectúa con posterioridad a la introducción de los zócalos de piedra, que, tal y como vimos, hacían su aparición a mediados del siglo $\mathrm{X}$, una circunstancia que creemos no debe ser leída tanto en clave de evolución técnica como de adaptación a nuevas necesidades espaciales y funcionales de la casa unitaria.

Aunque en numerosos contextos peninsulares y europeos esta tipología pervive más de medio milenio, el ejemplar registrado en las excavaciones de Santa María se mantendrá en uso durante apenas cien años, siendo substituida a inicios del siglo XII por la casa en altura.

4. El nuevo modelo de casa en altura se afianzó lentamente, debido a la complejidad constructiva que conllevaba: la elevación de verdaderos muros de fábrica superaba con creces los requerimientos tecnológicos de los elementales zócalos de piedra de periodos anteriores; y otro tanto cabe decir de las nuevas estructuras de madera que, como el pan de bois, exigía unos conocimientos de carpintería de mucha mayor especialización que la que los entrelazos de avellano y los manteados de arcilla habían requerido a los campesinos de centurias precedentes.

No es casual que, en este innovador ambiente técnico, se introduzcan nuevos materiales pétreos, como la calcarenita, seleccionada por sus excelentes propiedades mecánicas, necesarias para garantizar la solidez constructiva que exige la casa en altura, sin importar que su extracción y acarreo requiriera la ampliación de las áreas de captación en varios kilómetros. Como tampoco lo es que el aprovisionamiento de la madera se diversificara, como evidencia el aumento significativo en consumo de haya que muestran los análisis antracológicos, a pesar de que para ello tuvieran que desplazarse hacia las zonas cimeras de los montes del entorno.

Observamos, en definitiva, un acceso selectivo a los recursos que, junto a una mayor complejidad tecnológica, refleja la presencia de un artesanado especializado y un mayor coste económico de la casa, tanto en términos materiales como de mano de obra, que sólo podrá ser asumido por la población con mayor nivel adquisitivo. De hecho, la difusión de la casa en altura es vista en algunas regiones como un síntoma de la emergencia de importantes diferencias socioeconómicas entre la población, en una sociedad en la que una casa más amplia, más articulada y más compleja desde el punto de vista arquitectónico 


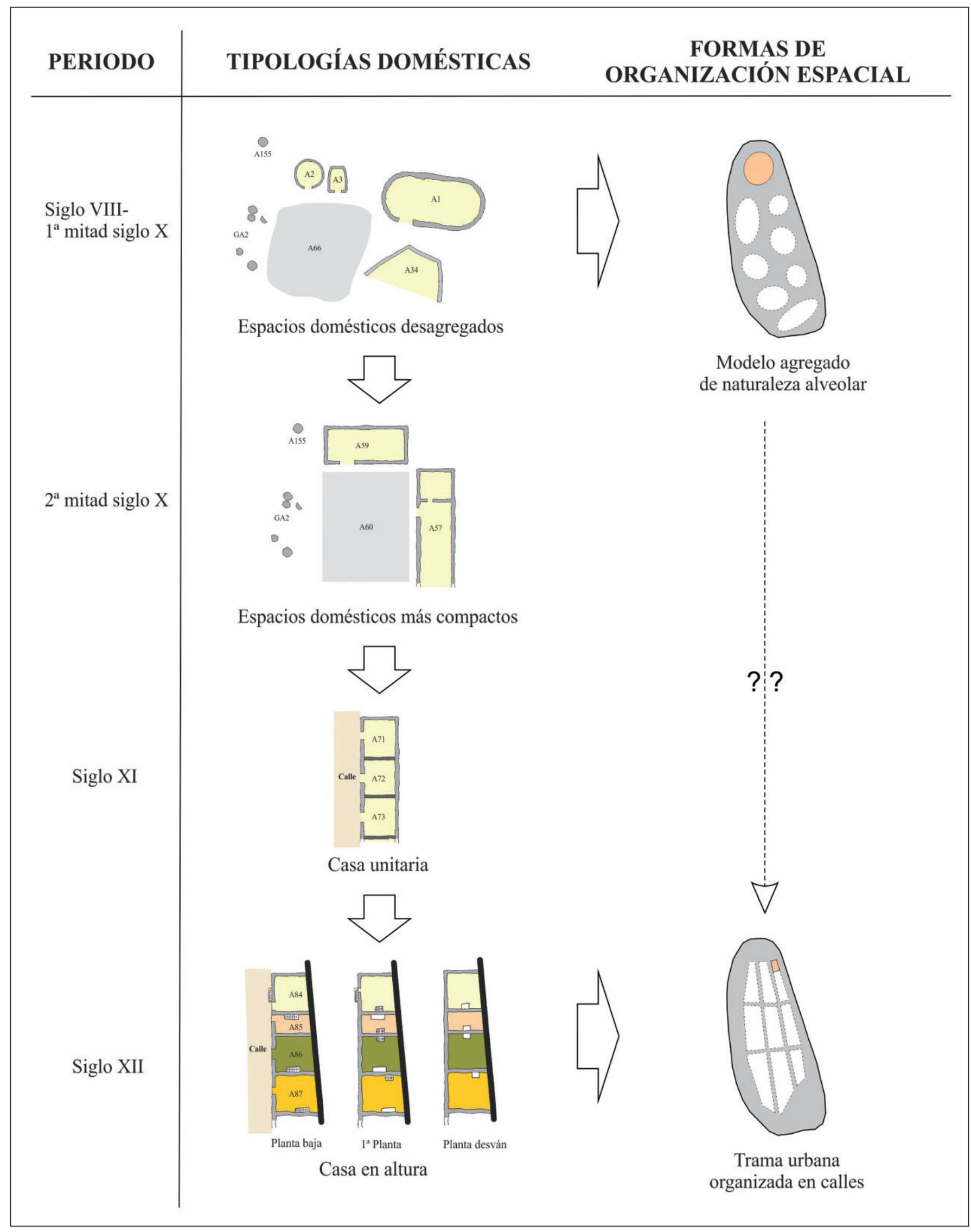

Fig. 22. Tipologías domésticas y patrones de organización espacial reconocidos en Gasteiz entre los siglos VIII y XII d.C 


\begin{tabular}{|c|c|c|c|c|c|}
\hline ACTIVIDAD & PLANTA & RECONSTRUCCIÓN & $\begin{array}{l}\text { ESTRUCTURA } \\
\text { PORTANTE }\end{array}$ & $\begin{array}{c}\text { MURO DE } \\
\text { CIERRE }\end{array}$ & CRONOLOGÍA \\
\hline A1 & & & $\begin{array}{l}\text { Armadura de } \\
\text { postes con } \\
\text { pavimento } \\
\text { sobreelevado }\end{array}$ & Clayonnage & $\begin{array}{l}\text { Siglo IX- } \\
1^{\text {a mitad S. X }}\end{array}$ \\
\hline A3 & & & $\begin{array}{l}\text { Armadura de } \\
\text { postes con } \\
\text { pavimento } \\
\text { a nivel de suelo }\end{array}$ & Clayonnage & $\begin{array}{l}\text { Siglo IX- } \\
1^{\text {a }} \text { mitad S. X }\end{array}$ \\
\hline A5 & & & $\begin{array}{l}\text { Armadura de } \\
\text { postes con } \\
\text { pavimento } \\
\text { semiexcavado }\end{array}$ & $\begin{array}{l}\text { No } \\
\text { identificado }\end{array}$ & $\begin{array}{l}\text { Siglo VIII- } \\
1^{a} \text { mitad S. IX }\end{array}$ \\
\hline A57 & & & $\begin{array}{l}\text { Con zócalo de } \\
\text { piedra }\end{array}$ & $\begin{array}{l}\text { Façonnage } \\
\text { direct }\end{array}$ & $\begin{array}{l}2^{\text {a mitad }} \\
\text { siglo X-S. XI }\end{array}$ \\
\hline A57 & & & $\begin{array}{l}\text { En técnica mixta } \\
\text { con zócalo de } \\
\text { piedra }\end{array}$ & $\begin{array}{l}\text { Façonnage } \\
\text { direct }\end{array}$ & $\begin{array}{l}2^{\text {a mitad }} \\
\text { siglo X-S. XI }\end{array}$ \\
\hline A77 & & & $\begin{array}{l}\text { En técnica mixta } \\
\text { con zócalo de } \\
\text { madera }\end{array}$ & Pan de bois & Siglo XI \\
\hline A83 & & & $\begin{array}{l}\text { Con muros de } \\
\text { piedra }\end{array}$ & Pan de bois & Siglo XII \\
\hline
\end{tabular}

Fig. 23. Tabla tipológica de técnicas constructivas (ss. VIII-XII d.C.) 
encarna el estatus social privilegiado de sus habitantes (Galetti, 2001: 48).

Los habitantes de nuestra casa gozaron sin duda de ese estatus privilegiado desde fechas muy tempranas, primero con la edificación de la longhouse en el espacio doméstico desagregado, después con la profunda modificación de la casa con patio y más tarde con la transformación en altura de la casa unitaria. Todo ello respetando el primitivo solar, lo que nos confirma la relevancia de las diferentes generaciones que habitaron el lugar, con capacidad suficiente para mantenerse tras la reurbanización urbana del asentamiento en el siglo XI, su posterior amurallamiento y la edificación de la primera iglesia de Santa María en pleno siglo XII.

\section{Bibliografía}

Alfaro, E., 2012, La arquitectura de Zaballa: materiales y técnicas constructivas, Arqueología del campesinado medieval: la aldea de Zaballa, Bilbao, pp. 493529.

Azkarate, A., 2007, Sobre las huellas iniciales de un asentamiento altomedieval en el País Vasco, en «Homenaje a Ignacio Barandiarán Maestu». Veleia, Vol. 24-25, Vitoria-Gasteiz, pp. 1283-1299.

Azkarate, A., 2008, La Arqueología de la Arquitectura en el siglo XXI, Arqueología de la Arquitectura 5, pp. 11-13

Azkarate, A., 2011, Archeologia dell'Architettura in Spagna, Archeologia dell'Architettura 7, pp. 15-26.

Azkarate, A. La construcción y lo construido. Arqueología de la Arquitectura, en Quirós, J.A. (Dir.), La materialidad de la historia, Ed. Akal, (e.p.).

Azkarate, A., Cámara; L., Lasagabaster, J. I., Latorre, P., 2001, Catedral de Santa María de Vitoria-Gasteiz. Plan Director de Restauración, Vitoria-Gasteiz.

Azkarate, A., Martinez, J.M., Solaun, J.L., 2011, Metalurgia y hábitat en el País Vasco de época medieval: el asentamiento ferrón de Bagoeta, Álava (ss. VIIXIV d.C.), Arqueología y Territorio Medieval 18, pp. 71-89.

Azkarate A., Quirós, J.A., 2001, Arquitectura doméstica altomedieval en la Península Ibérica. Reflexiones a partir de las excavaciones arqueológicas de la catedral de Santa María de Vitoria-Gasteiz, País Vasco, Archeologia Medievale XXVIII, pp. 25-60.

Azkarate, A., Solaun, J.L., 2003, Después del Imperio Romano y antes del año mil: morfología urbana, técnicas constructivas y producciones cerámicas, Arqueología de la Arquitectura 2, pp. 37-46.

Azkarate, A., Solaun, J.L., 2009, Nacimiento y transformación de un asentamiento altomedieval en un futuro centro de poder: Gasteiz desde fines del siglo VII d.C. a inicios del segundo milenio, The archaeology of early medieval villages in Europe, Vitoria-Gasteiz, pp. 405-428.

Bardou, P., Arzoumanian, V., 1979, Arquitecturas de adobe, Barcelona.

Bermejo, J., 2009, Leyendo los espacios: una aproximación crítica a la sintaxis espacial como herramienta de análisis, Arqueología de la Arquitectura, 6, pp.47-62.

Bourdieu, P., 1993, El sentido práctico, Madrid, Taurus.

Cagnana, A., 2000, Archeologia dei materiali da construzione, Manuali per l'archeologia 1, Mantova.

Chapelot, J., Fossier, R., 1980, Le Village et la Maison au Moyen Age, Paris.

Chazelles-Gazzal de, C. A., 1997, Les maisons en terre de la Gaule méridionale, Monographies instrumentum 2.

Eco H., 1968, La estructura ausente. Introducción a la semiótica, Barcelona, Lumen.
Fiorani, D., 1996, Techniche costruttive murarie medievali: il Lazio meridionale, Roma.

Foucault, M., 1984, Vigilar y Castigar [Paris, 1975], Madrid, Siglo XXI.

Fronza, V., Valenti, M., 1996, Un archivio per l'edilizia in materiale deperibile nell'altomedioevo, in Valenti M. (a cura di), Poggio Imperiale a Poggibonsi (Siena). Dal villaggio di capanne al castello di pietra. I. Diagnostica archeologica ecampagne di scavo 1991-1994, Firenze, pp. 159-218.

Fronza, V., 2008, Tecniche costruttive in legno e in terra, in Valenti M. (a cura di), Miranduolo in alta Val di Merse (Chiusdino - SI), Archeologia su un sito di potere del Medioevo toscano, Firenze, pp. 245-281.

Galetti, P., 2001, Uomini e case nel Medioevo tra Occidente e Oriente, Segrate.

García Camino, I., 1998, La vivienda medieval: perspectivas de investigación desde la arqueología, La vida cotidiana en la Edad Media, VIII Semana de Estudios medievales, Nájera, 1997, pp. 77-110.

González Ruibal, A., 2001, Etnoarqueología de la vivienda en África subsahariana: aspectos simbólicos y sociales, Arqueoweb, 3 (2).

Gutiérrez Lloret, S., Cañavate, V., 2010, Casas y cosas: espacios y funcionalidad en las viviendas emirales del Tolmo de Minateda (Hellín, Albacete), Espacios de vida, Cuadernos de Madinat al-Zahra 07, pp. 123-148.

Hamerow, E., 2002, Early medieval settlements. The archaeology of rural communities in Northwest Europe, 400-900, Oxford.

Heidegger M., 1994, Conferencias y artículos, Barcelona, Serval.

Hillier B., Hanson J., 1984, The Social Logic of Space, Cambridge, Cambridge University Press.

Martínez Torres, L.M., 1999, Mapa litológico y procedencia de las rocas empeladas en la catedral vieja de Santa María de Vitoria-Gasteiz, Estudios del Museo de Ciencias Naturales de Álava, vol. 14, pp. 5-13.

Martínez Torres, L.M., 2003, La tierra de los pilares, Universidad del País Vasco, Bilbao.

Nielsen, A.E., 2001, Evolución del espacio doméstico en el norte de Lípez (Potosí, Bolivia): ca. 900-1700 d.C., Estudios Atacameños, n 21, San Pedro de Atacama, pp. 41-62.

Pérez Soler, M.D., 1970, Cartulario de Valpuesta, Valencia.

Quirós, J.A., 2009, Arqueología del campesinado altomedieval: las aldeas y las granjas del País Vasco, The archaeology of early medieval villages in Europe, Bilbao, pp. 385-403.

Quirós, J.A., 2012, La arquitectura doméstica en los yacimientos rurales en torno al 711, En torno al 711, Arqueología e Historia entre dos mundos, vol. II, Zona Arqueológica, $n^{\circ} 15$, pp. 63-82.

Quirós, J.A., 2012, Arqueología del campesinado medieval: la aldea de Zaballa, Bilbao.

Rapoport A., 1976 (ed.), The Mutual Interaction of People and Their Built Environment, Mouton, The Hague, Mouton.

Sánchez García, A., 1999, «Las técnicas constructivas con tierra en la arqueología prerromana del País Valenciano", Quaderns de Prehistòria i Arqueología de Castelló, 20, pp. 166-169.

Steadman S., 1996, Recent research in the archaeology of architecture: beyond the foundations, Journal of Archaeological Research, vol 4, no 1, pp. 51-93.

Tipper, J., 2000, Grubenhauser: pit fills and pitfalls, Cambridge.

Tipper, J., 2004, The Grubenhaus in Anglo-Saxon England, An analysis and interpretation of the evidence from a most distinctive building type, Yeddingham.

Valenti, M., 2004, L'insediamento altomedievale nelle champagne toscane. Paesaggi, popolamento e villaggi tra VI e X secolo, Firenze.

Wilk, R., Rathje, W., 1982 Household archaeology, American behavioral scientist 25(6), pp. 617-639.

Witmore C., 2007, Arqueología simétrica: un manifiesto breve, Complutum, Vol. 18, pp. 305-319

Zarankin A., 2005, Arqueología de la Arquitectura, modelando al individuo disciplinado en la sociedad capitalista, Revista de Arqueología Americana 22, pp. 25-41. 